\title{
Egalitarian feeds forward to Staufen to inhibit Dynein during mRNP transport
}

\author{
Imre Gáspár ${ }^{1,2}{ }^{*}$, Ly Jane Phea ${ }^{1}$ and Anne Ephrussi ${ }^{1}$ *
}

1 Developmental Biology Unit, European Molecular Biology Laboratory, 69117 Heidelberg, Germany

2 Current address: Max Planck Institute of Biochemistry, Martinsried, Germany.

*Correspondence: gaspar@biochem.mpg.de, anne.ephrussi@embl.org 


\begin{abstract}
The regulated recruitment and activity of motor proteins is crucial for intracellular transport of cargoes, including ribonucleoprotein complexes (RNP). Here we show that regulation of mRNP transport by the minus end-directed dynein motor complex in the Drosophila germline relies on the interplay of two double-stranded RNA binding proteins, Staufen and the dynein adaptor Egalitarian. Our quantitative in situ analysis shows that, in the nurse cells, Egalitarian associates with bicoid, oskar and staufen mRNAs, which consequently enrich in the oocyte. This results in ooplasmic accumulation of Staufen and its recruitment to the transcripts. We demonstrate that Staufen levels scale proportionately with RNA content in oskar mRNPs, and to a lesser extent in bicoid mRNPs. We show that enhanced recruitment of Staufen to oskar mRNPs results in dissociation of Egalitarian and a reduction in minus end-directed transport, although dynein remains associated with the RNPs. The downregulation of dynein activity prevents anterior accumulation of oskar mRNA, whose transport to the posterior is essential for localized production of Oskar protein. Our observations identify a feed-forward loop, whereby staufen mRNA localization and protein accumulation in the oocyte enable motor switching, promoting oskar mRNA localization to the posterior pole.
\end{abstract}

\title{
Introduction
}

Proper execution of the genetic program relies on numerous regulatory mechanisms that act at multiple levels of gene expression, from transcription to post-translational events, such as protein modification or RNA decay. In large cells, such as neurons, early embryos and oocytes, one key process that dynamically regulates genetic output at the subcellular level is RNA localization, which often relies on active, cytoskeletal motor-dependent intracellular transport (Gaspar 2011; Glock et al. 2017; Marchand et al. 2012; St Johnston 2005; Mofatteh and Bullock 2017).

As for other types of intracellular cargoes, the transport machineries involved in RNA localization consist of cytoskeletal tracks (microtubules or microfilaments) and molecular motors capable of active transport (Eliscovich and Singer, 2017; Gaspar, 2011; Mofatteh and Bullock, 2017; St Johnston, 2005). These motors include kinesin-1 and cytoplasmic dynein, which were shown to be involved in the transport of different mRNPs along microtubules (Gaspar, 2011; Mofatteh and Bullock, 2017). A paradigm for the study of mRNP transport is is oskar mRNA, which is produced in the nurse cells of the Drosophila germline syncytium and transported into the developing oocyte by cytoplasmic dynein (Clark et al., 2007; Ephrussi et al., 1991; Jambor et al., 2014; Januschke et al., 2002; Sanghavi et al., 2013; Vazquez-Pianzola et al., 2017). Khc was shown to be also recruited to oskar mRNPs in the nurse cells (Gáspár et al., 2017). During mid-oogenesis, when the microtubule cytoskeleton is reorganized, oskar mRNA is transported by Kinesin heavy chain (Khc) to the posterior pole (Brendza et al., 2000; Palacios and St Johnston, 2002; Williams et al., 2014; Zimyanin et al., 2008), where the microtubule plus ends are focused (Parton et al., 2011; Sanghavi et al., 2013). The dsRNA binding protein (dsRBP), Staufen is necessary for this second phase 
of oskar localization (St Johnston et al., 1991; St Johnston et al., 1992; Zimyanin et al., 2008). Staufen has a dual function: it is also required for production of Oskar protein, which induces abdomen and germline formation in the embryo (Ephrussi and Lehmann, 1992; Micklem et al., 2000; Schuldt et al., 1998; St Johnston et al., 1991). Staufen is also involved in transport and/or localization of other mRNAs, such as bicoid in the oocyte and prospero in dividing neuroblasts (Ferrandon et al., 1994; Schuldt et al., 1998). Mammalian orthologues of the Drosophila Staufen, mStau1 and mStau2, were also shown to be involved in the bidirectional transport of CaMKIla and Rgs4 mRNAs in dendrites, indicating that Staufen function as a regulator of RNP transport is evolutionarily conserved (Bauer et al., 2019; Heraud-Farlow et al., 2013). In line with this hypothesis, we have demonstrated that mStau2 can partially substitute for DmStaufen in oskar mRNA localization (Heber et al., 2019). Recently dozens of potential RNA targets of Staufen were identified by RNA immunoprecipitation coupled with sequencing, each containing one or more bioinformatically defined Staufen Recognized Structures (SRS) (Laver et al., 2013). The SRS and the binding site in oskar mRNA for the dynein adaptor dsRBP Egalitarian (Amrute-Nayak and Bullock, 2012; Dienstbier et al., 2009; Vazquez-Pianzola et al., 2017) are in close proximity and were shown to be important for posterior localization of the mRNA (Mohr et al., 2021).

Here, we show that Staufen is primarily expressed in the developing oocyte, where it is recruited to oskar mRNPs. Staufen recruitment leads to dissociation of Egalitarian and reduction of cytoplasmic dynein activity on the mRNPs. We find that Egalitarian also interacts with staufen mRNPs and is responsible for the ooplasmic enrichment of staufen mRNA and, consequently, of Staufen protein. We find that an interference between Staufen and Egalitarian regulates ooplasmic transport of oskar, as well as of staufen and of the anterior localizing bicoid mRNPs. Our findings highlight a feed-forward loop involving Egalitarian-mediated localized expression of Staufen, which regulates the activity of RNP-associated cytoplasmic dynein during oogenesis.

\section{Results}

\section{Staufen suppresses minus end-directed transport of oskar mRNPs}

In staufen mutant oocytes (relative absence of Staufen protein), enrichment of oskar mRNA at the posterior pole is greatly reduced compared to wild-type, and a considerable amount of oskar remains near the anterior margin of the oocyte (Fig 1A'; Ephrussi et al., 1991; St Johnston et al., 1991). Furthermore, high-resolution ex vivo analysis of oskar-MS2 RNP motility by TIRF microscopy (Video S3 and S4; Gaspar and Ephrussi, 2017; Gáspár et al., 2017) revealed that the usual, approximately 2:1 dominance of microtubule plus end- versus minus end-directed oskar mRNP runs observed in wild-type samples is lost in stau RNAi ooplasmic extracts (Fig 1B). The distribution of oskar mRNA and the directionality of mRNP transport in staufen mutants differ from what is observed in other mutants affecting oskar localization, such as $\operatorname{Tm}^{\text {gs }}$ (Fig 1A" and (Gáspár et al., 2017) and khc ${ }^{\text {null }}$ (Brendza et al., 2000; Gáspár et al., 2017; Williams et al., 2014; Zimyanin et al., 2008), in which oskar mRNA fails to localize at the posterior of the oocyte, and polarity of the runs is reversed as a 
result of compromised loading and activity of the plus end-directed motor, kinesin-1 (Gáspár et al., 2017).

In vivo, consistent with what was previously reported (Zimyanin et al., 2008), we found that the fraction of motile oskar RNPs was greatly reduced in staufen mutants (Video S1 and S2), explaining the reduction in posterior localization of oskar. However, co-detection of functional, endogenously tagged fluorescent Khc molecules and smFISH against oskar, did not reveal a reduction in motor association with the mRNPs in the absence of Staufen (Fig 1C). Moreover, analysis of the speed and length of oskar RNP runs upon staufen knock-down (Fig 1D and E) indicated that kinesin activity was not compromised. Interestingly, however, runs towards microtubule minus ends increased in speed and processivity when Staufen levels were reduced (Fig 1D and E), indicating that the loss of plus end dominance of oskar mRNP runs is due to hyperactivity of the minus end-directed dynein transport machinery.

Altogether, these findings point to a role of Staufen in suppression of the minus end-directed transport of oskar RNA by cytoplasmic dynein (Clark et al., 2007; Jambor et al., 2014). For instance, hyperactivity of the dynein motor in the presence of gain-of-function mutations in the dynein cargo-adapter, Bicaudal-D (Liu et al., 2013; Navarro et al., 2004) is considered to be a reason for the anterior accumulation of oskar RNA, as we also observe in staufen mutant oocytes (Fig 1A', St Johnston et al. 1991). 


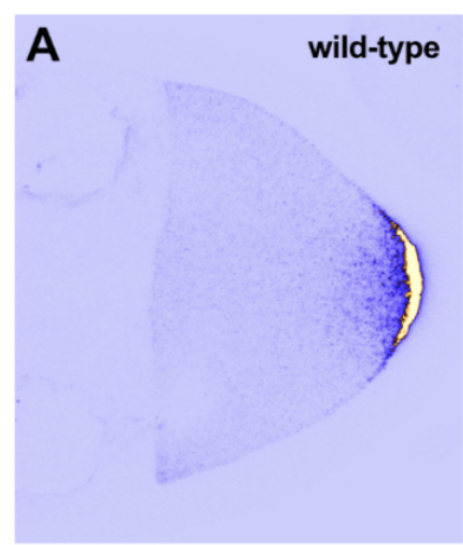

B

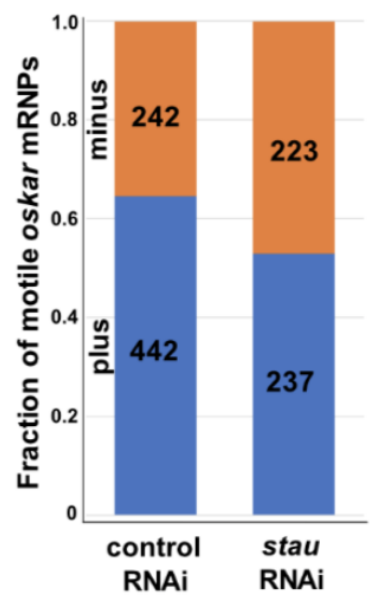

D

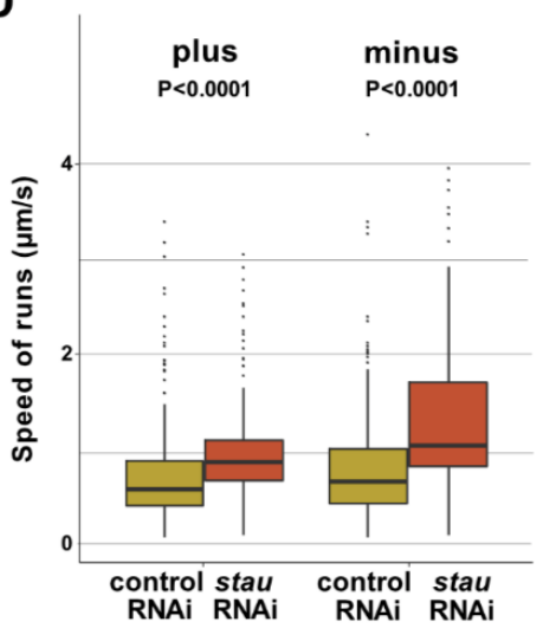

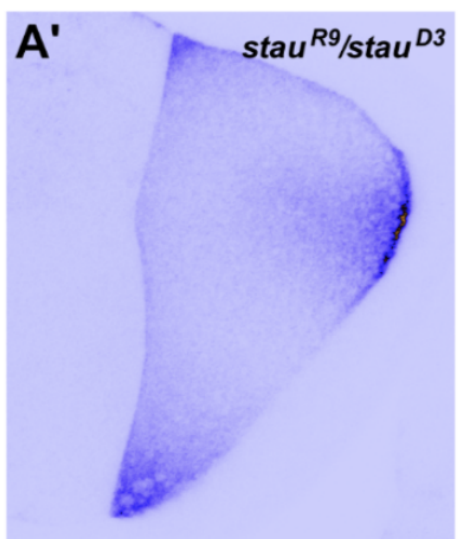
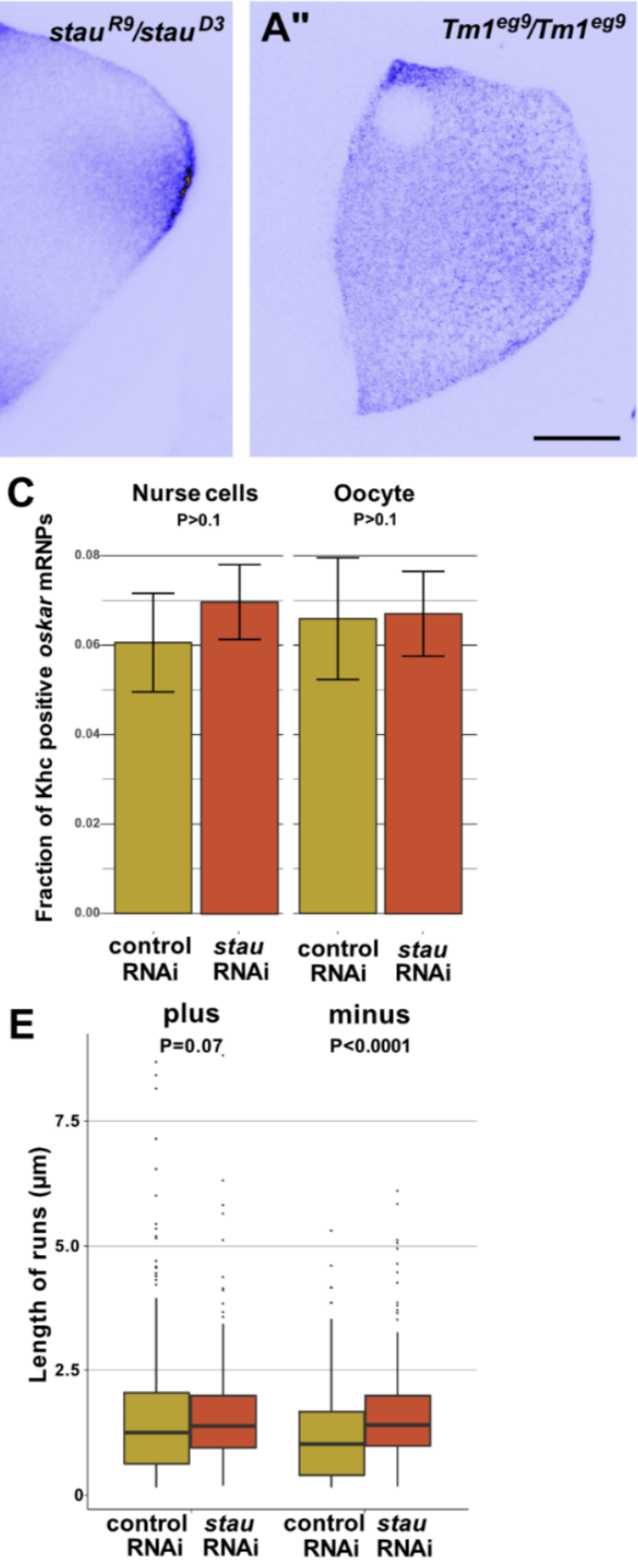

Figure 1: Effects of loss of Staufen on oskar RNA localization and transport. (A-A") Localization of oskar mRNA in wild-type (A) Staufen null (A') and Tm1-I/C null oocytes (A"). Scale bar represents $20 \mu \mathrm{m}$ (B) Polarity distribution of oskar mRNP motility ex vivo in the presence (control RNAi) or absence of Staufen (stau RNAi). Numbers indicate the number of oskar mRNP runs measured in the corresponding category. See also Video S3 and S4. (C) Khc association with oskar mRNPs in situ in the nurse cells and in the oocyte, in presence (brown) or absence (red) of Staufen. P-values of pairwise Student's t-tests are shown. (D-E) Speed (D) and travelled distance (E) of motile oskar mRNPs in vivo, toward the plus or minus ends of microtubules in the presence (brown) and absence (red) of Staufen. P-values of pairwise Mann Whitney U-tests are shown. 


\section{A balance of Staufen and Egalitarian is required for oskar mRNA localization}

The distribution of oskar mRNA can vary between oocytes of the same genotype and oogenetic stage. The oskar mislocalization phenotype observed in staufen mutant oocytes is particularly variable, from no accumulation at the posterior, to almost wild-type posterior localization. To obtain a representative, quantifiable view of oskar mRNA distribution in staufen oocytes, we applied a statistical averaging method (Ghosh et al. 2012; Gaspar et al. 2014) and found a strong anterior accumulation of the RNA in the absence of Staufen, as indicated by the strong signal in the anterior "corners" of the oocyte matrix, and a weak enrichment of oskar at the posterior (Fig 2A and B and Fig S1 A, B, E). A similar phenotype was observed when either the dsRNA binding protein, Egalitarian - which mediates the interaction between RNA molecules and the dynein machinery (Amrute-Nayak and Bullock, 2012; Dienstbier et al., 2009; Navarro et al., 2004) - was overexpressed (Fig 2C; Mohr et al., 2021), or when a gain-of-function Bicaudal-D protein was expressed in the female germ-line (Fig 2E and Fig S2A).

The phenotypic similarity between stau null and Egalitarian overexpressing or $B i c D^{1 /+}$ egg-chambers with respect to oskar RNA distribution suggested that in these contexts a relative lack of Staufen activity might be the cause of the anterior accumulation of oskar. To test this hypothesis, we overexpressed Staufen in the germline of Egalitarian overexpressing or $B i c D^{1} /+$ females. In both cases, the anterior accumulation of oskar disappeared and the RNA enriched exclusively at the posterior pole (Fig 2D, F and Fig S2A, B). Moreover, upon removal of a functional copy of egalitarian in egg-chambers with reduced Staufen levels, we observed a moderate rescue of the oskar mislocalization (Fig S2C-E, stau RNAi, egl/1/+). Such moderate rescue was expected as oskar RNPs entering the oocyte are thought to be associated with the dynein cargo-adapter Egalitarian. Nevertheless, these phenotypic rescue experiments indicate that Staufen and the Egalitarian/dynein machinery negatively interact at least at the genetic level - with each other. 
bioRxiv preprint doi: https://doi.org/10.1101/2021.04.24.441269; this version posted April 25, 2021. The copyright holder for this preprint (which was not certified by peer review) is the author/funder, who has granted bioRxiv a license to display the preprint in perpetuity. It is made available under aCC-BY-NC-ND 4.0 International license.
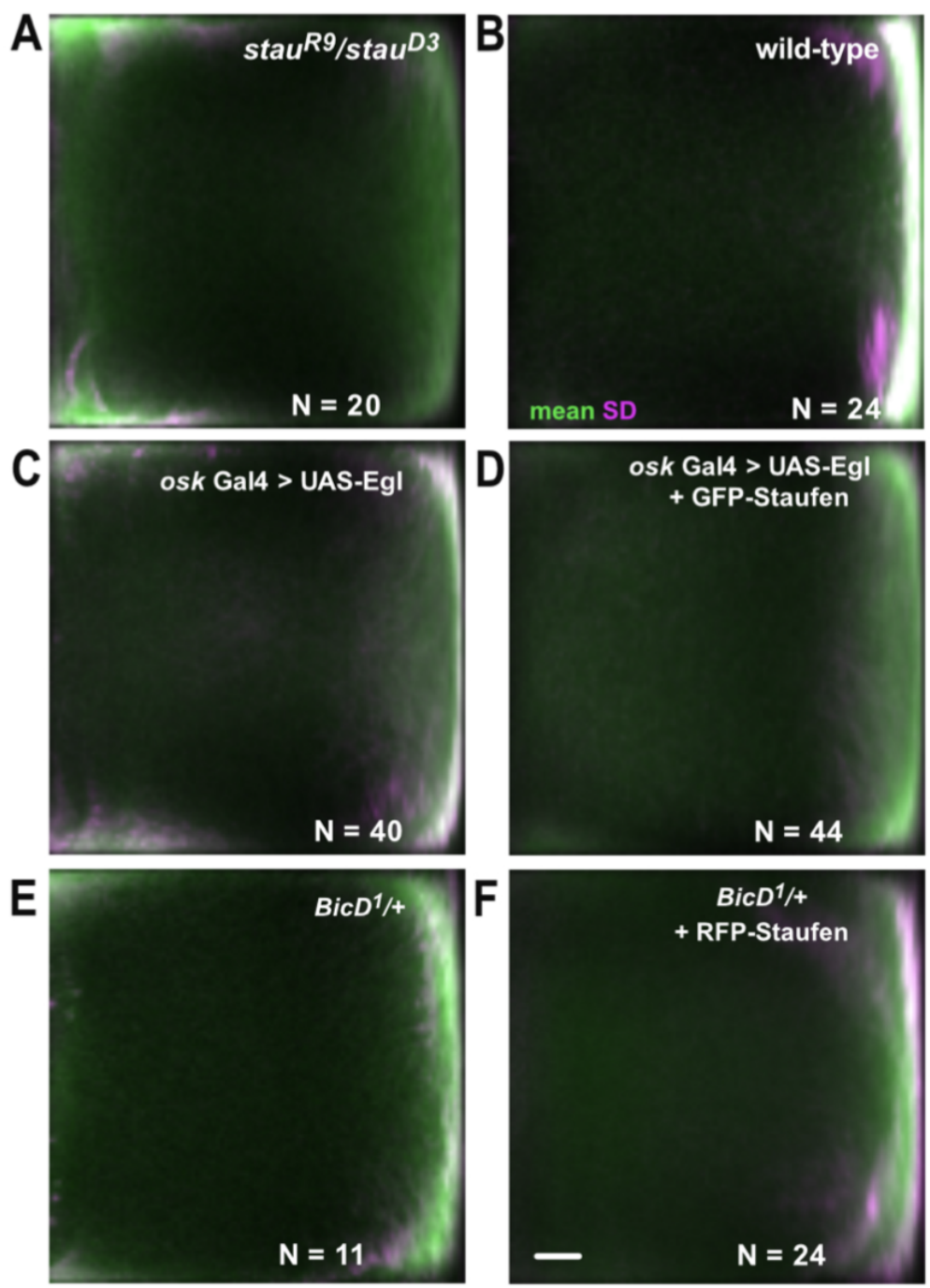

Figure 2: Staufen and Egalitarian interfere during the localization of oskar mRNA. (A-F) Average distribution of oskar mRNA (green) and variability of its distribution (SD, magenta) in stage 9 oocytes (anterior to the left, posterior to the right). Besides the normal posterior localization of oskar, a pronounced anterior accumulation is observed in oocytes that lack Staufen protein (A), overexpress Egalitarian (C) or are heterozygous for one copy of the dominant $B i c D^{1}$ allele $(E)$. Such anterior accumulation of oskar is not observed in wild-type oocytes (B), nor upon Staufen overexpression in Egalitarian overexpressing oocytes (D) or in $B i c D^{1 /+}$ oocytes (F). $\mathrm{N}$ indicates the number of oocytes analysed. Scale-bar represents $10 \%$ of anteroposterior axis length. 
bioRxiv preprint doi: https://doi.org/10.1101/2021.04.24.441269; this version posted April 25, 2021. The copyright holder for this preprint (which was not certified by peer review) is the author/funder, who has granted bioRxiv a license to display the preprint in perpetuity. It is made available under aCC-BY-NC-ND 4.0 International license.
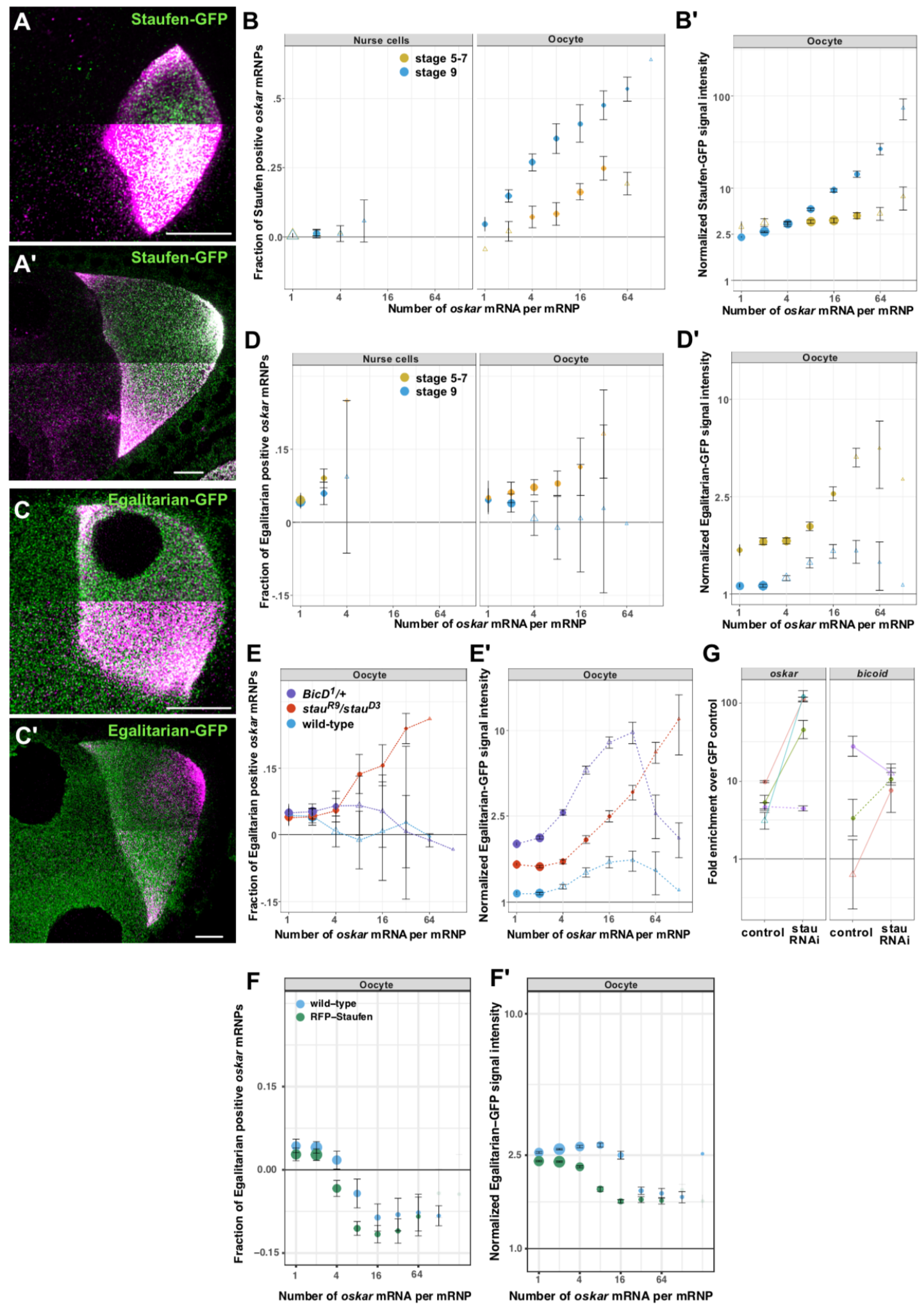

Figure 3: Staufen interferes with Egalitarian association with oskar mRNPs in the oocyte.

(A-A') Distribution of Staufen-GFP (green) prior to (stage 6-7, A) and during (stage 9, A') the posterior localization of oskar mRNA (magenta). (B-B') Association of Staufen-GFP with oskar mRNPs before (yellow) and during (blue) the posterior localization of oskar mRNA. (A-B') Endogenous Staufen was absent $\left(\operatorname{stau}^{R 9} / \mathrm{stau}^{D 3}\right)\left(\mathrm{C}-\mathrm{C}^{\prime}\right)$ Distribution of Egalitarian-GFP (green) before (stage 7, C) and during (stage 9, C') the posterior localization of oskar mRNA (magenta). (A, A', C and C') Lower half of panels shown 
with different brightness/contrast settings to allow appreciation of the signal in the nurse cells. Scale bars represent $10 \mu \mathrm{m}$. (D-D') Association of Egalitarian-GFP with oskar mRNPs before (yellow) and during (blue) the posterior localization of oskar mRNA. (E-E') Association of Egalitarian-GFP with oskar mRNPs during stage 9 in the presence (blue) or in the absence (red) of Staufen, or in presence of the dominant $B i c D^{1}$ mutation (magenta) in the oocyte. (F-F') Association of Egalitarian-GFP with oskar mRNPs in stage 9 oocytes upon mild overexpression of Staufen. (C-F') Endogenous, unlabeled Egalitarian was present. (B, D-F) The fraction of Staufen-GFP (B) or Egalitarian-GFP (D-F) positive oskar mRNPs as a function of the mRNA content of the RNPs in the nurse cells and in the oocyte. (B', D'-F') Normalized Staufen-GFP (B') or Egalitarian-GFP (D'-F') signal intensity as function of oskar mRNA content in the mRNPs. (B, B', D-F') Error bars represent $95 \%$ confidence intervals, the size of the circles is proportional to the relative abundance of the given sized oskar mRNPs within the entire sample analysed. (G) Fold-enrichment of two Egalitarian target mRNAs, oskar and bicoid, in RNA pulldown experiments using Egalitarian-GFP as a bait, in the presence (control) or in the absence of Staufen (stau RNAi). Different colours represent different experiments. Paired data are connected with solid $(p<0.05)$ or dashed lines $(p>0.05)$, indicating significance as determined in pairwise Student's t-test. Empty triangles indicate non-significant $(p>0.05)$ enrichment relative to the GFP control. Error bars show standard deviation.

\section{Staufen dissociates Egalitarian from oskar mRNPs in the oocyte}

To shed further light on the relationship and the potential interference between Staufen and the dynein machinery, in particular its RNA binding subunit Egalitarian, we examined the association of each protein with oskar mRNA by in situ colocalization using smFISH in combination with transgenically expressed fluorescently tagged proteins of interest.

In the oocyte, Staufen-GFP and oskar mRNA signals frequently overlapped, whereas little overlap and only low levels of Staufen-GFP signal were observed in the nurse cells, regardless of the developmental stage of the egg-chamber (Fig 3A and A'). Quantitative analysis of oskar mRNA and Staufen colocalization confirmed the absence of an association in the nurse cells (Fig 3B), as previously reported (Little et al., 2015). Quantifying oskar mRNA copy number by smFISH (Fig S3A), we found that the fraction of Staufen-associated oskar mRNPs in the oocyte increased as a function of oskar mRNA content, and the increase was substantially more pronounced during stage 9 than in earlier stages of oogenesis (Fig 3B). During stage 9, not only the likelihood of Staufen association but also the relative levels of Staufen - as reported by the normalised Staufen-GFP signal - increased and this increase was highly linear (Fig 3B' and Fig S3C), similarly to what we reported for overexpressed Staufen and mammalian Stau2 (Heber et al., 2019). Prior to the onset of oskar localization, Staufen levels showed no scaling with oskar mRNA content of the mRNPs (Fig 3B').

During similar stages of oogenesis, Egalitarian was also present in both the nurse cells and in the oocyte (Fig $3 \mathrm{C}$ and $\mathrm{C}^{\prime}$ ). Colocalization analysis showed that, contrary to Staufen, Egalitarian is associated with oskar mRNPs already in the nurse cells (Fig 3D). The protein maintained its association with oskar in the oocyte until the onset of posterior localization, but during stage 9 , we detected no significant colocalization between Egalitarian-GFP and mRNPs that contained four or more copies of oskar mRNA (Fig 3D). We also found that the relative amount of Egalitarian signal associated with oskar mRNPs was approximately two-fold higher during the early stages of oogenesis than in their stage 9 counterparts (Fig 3D'). In fact, the amount of Egalitarian signal associated with the mRNPs increased proportionately with oskar mRNA content during early oogenesis, but was significantly reduced and independent of oskar mRNA copy number during posterior 
localization of the RNA (Fig S3D). While removal of endogenous unlabelled Egalitarian from stage 9 oocytes (egl $/ \mathrm{egl} \mathrm{l}^{2}$ rescued by the Egalitarian-GFP transgene) resulted in an increase in the fraction of oskar mRNPs associated with Egalitarian-GFP (Fig S3F), it did not affect the relative amount of Egalitarian-GFP on the RNPs (Fig S3F'). This indicates that in stage 9 oocytes the amount of Egalitarian per oskar RNP drops to a minimum (possibly one molecule). Upon moderate overexpression of Egalitarian-GFP (two copies of the transgene, Fig 6D), the relative amount of Egalitarian on oskar RNPs doubled, yet remained independent of the RNA content of the RNPs in stage 9 oocytes. This confirms our findings on the differing modes of association between oskar and this RNA binding protein during the early and mid stages of oogenesis.

The opposing trends of Staufen and Egalitarian association with oskar mRNPs in the nurse cells and the oocyte (Fig 3B,B' and D,D'), and the increasing concentrations of Staufen in the ooplasm prior to the onset of oskar localization (Fig S3G) suggest that the absence of Egalitarian association with oskar mRNPs in the oocyte might be brought about by Staufen. This would be consistent with the finding that SRS activity interferes with the function of the TAS (Mohr et al., 2021). To test the impact of Staufen on Egalitarian binding, we analysed Egalitarian association with oskar mRNPs in staufen mutants. When Staufen protein was absent or greatly reduced, Egalitarian remained associated with oskar mRNPs in stage 9 oocytes, and the relative amount of Egalitarian signal colocalizing with the RNPs increased with oskar mRNA content (Fig 3E, E' and Fig S3 E, E'). Conversely, when Staufen was mildly overexpressed, the amount of Egalitarian associated with larger oskar RNPs in the oocyte decreased (FIG 3F, F').

To test biochemically whether presence of Staufen affects the association of Egalitarian with oskar mRNPs, we performed UV crosslinking and GFP immunoprecipitation followed by quantitative PCR on egg-chambers co-expressing Egalitarian-GFP and staufen RNAi in the germline (Fig 3F, Fig S3H). Substantially more oskar mRNA was cross-linked to and co-immunoprecipitated with Egalitarian-GFP from extracts of egg-chambers expressing staufen RNAi than the white RNAi control (Fig 3G).

\section{Aberrant anterior localization of oskar mRNA correlates with increased Egalitarian association}

Bicaudal-D is a direct binding partner of Egalitarian, linking the mRNA cargo to the dynein motor (Dienstbier et al., 2009; Liu et al., 2013; Vazquez-Pianzola et al., 2017). Analysis of two gain-of-function Bic-D mutants revealed an increase in Egalitarian association with mid-sized (4-16 RNA copies) oskar mRNPs when compared to the wild-type control (Fig 3E, E' and Fig S3F, F'). Although the extent of Egalitarian association differed between the two alleles, in both cases the amount of Egalitarian-GFP associated with the mRNPs scaled with oskar RNA copy number up to 32 copies, in contrast with the low amount of Egalitarian-GFP detected on all oskar mRNPs in wild-type stage 9 egg-chambers (Fig E' and Fig S3F').

The anterior localization of oskar mRNA in the oocyte observed when Egalitarian is overexpressed (Fig 2C) might be due to an aberrant, concentration-dependent retention of the protein on the mRNPs. Indeed, in this context we observed numerous large RNP 
granules containing high amounts of Egalitarian-GFP (and possibly unlabelled Egalitarian), oskar mRNA, and often bicoid mRNA (Fig 4 A and $A^{\prime}$ ) in the nurse cells and at the anterior cortex of the oocyte. Such RNPs are not present when Egalitarian levels are close to wild-type (Fig 4E and 6C); furthermore, they do not appear to reach the posterior pole of oocytes overexpressing Egalitarian protein (Fig 4A and B). Quantification of the association of Egalitarian-GFP with oskar showed that when the protein was overexpressed, the relative Egalitarian-GFP signal scaled with oskar RNA content in the mRNPs (Fig 4C') - similar to what was observed in the absence of Staufen, and in egg-chambers expressing Bicaudal-D gain-of-function alleles (Fig 3E' and S3F'). On the other hand, we found no significant change in Staufen association with oskar mRNPs in stage 9 oocytes overexpressing Egalitarian (Fig 4D and D'), indicating that Egalitarian does not interfere with the loading of Staufen on oskar mRNPs. However, although the RNPs are associated with large amounts of Staufen, an abnormal proportion of high copy number oskar mRNPs (10 times more than in wild-type) fail to leave the vicinity of the anterior pole (Fig 4E).

Taken together, these data strongly suggest that a principal cause of oskar mislocalization to the anterior in the absence of Staufen, upon Egalitarian overexpression, and in gain-of-function BicD mutants is the failure to release Egalitarian from the RNPs during mid-oogenesis. This release appears to be mediated by Staufen, which interferes with the association of Egalitarian with oskar mRNPs, especially those with high oskar mRNA content. 

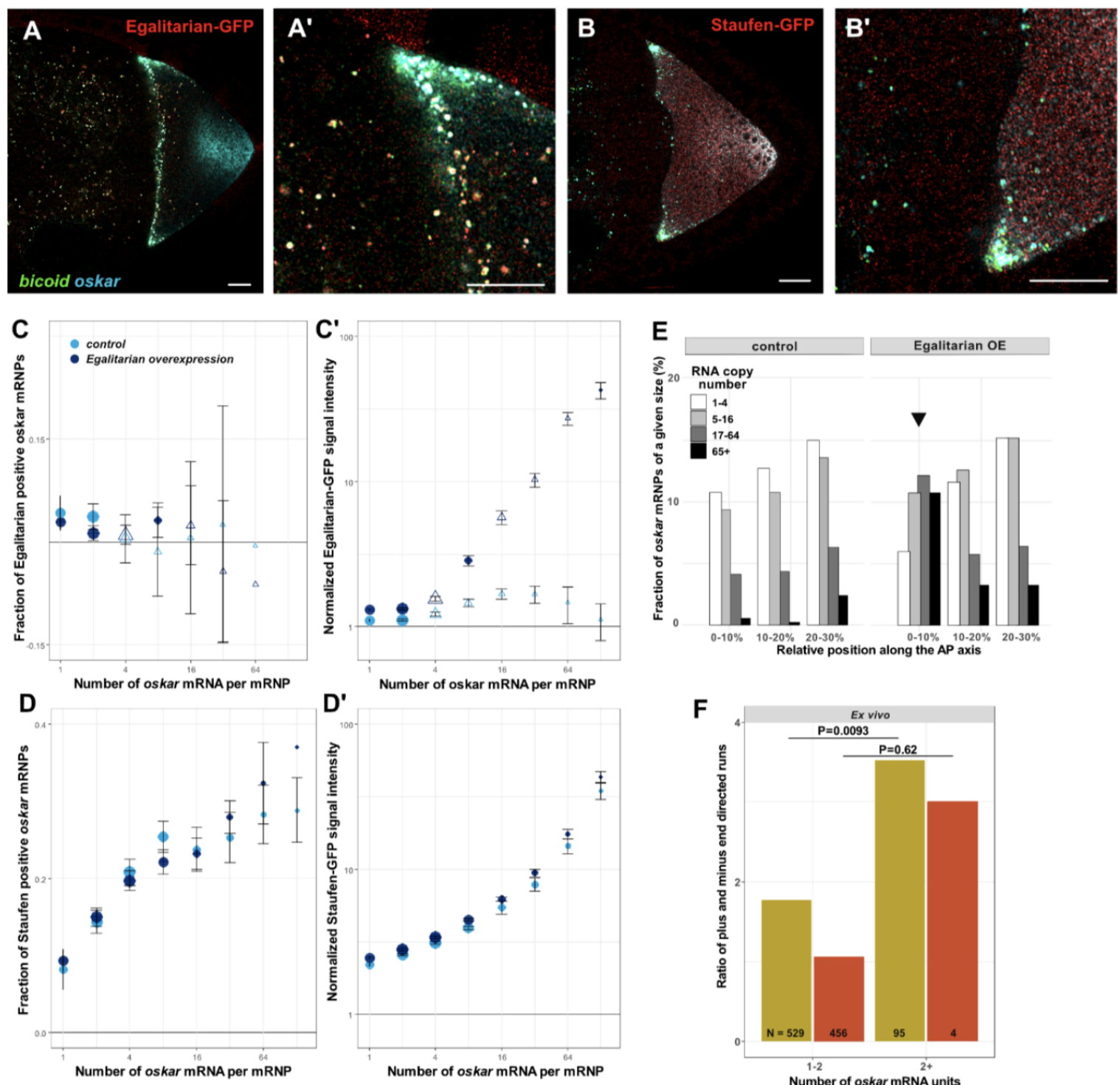

Figure 4: Effect of Egalitarian overexpression on oskar mRNP localization and composition.

(A-B') Stage 9 egg-chambers overexpressing Egalitarian in the germline (see Materials and Methods). The UASp-egalitarian transgene is under the control of the oskar-Gal4 driver. Large RNPs containing oskar and/or bicoid mRNA are observed in the nurse cells and in the oocyte, near the anterior. These RNPs colocalize with Egalitarian-GFP, expressed from a single copy of the transgene (A, A'). In the case of Staufen-GFP, expressed from a single copy of transgene, no or moderate colocalization in the nurse cells and at the anterior of the oocyte, respectively, is observed (B, B'). Scale bar represents 10 microns. (C-D') Fraction (C, D) of GFP positive oskar mRNPs and relative levels of Egalitarian-GFP (C') and Staufen-GFP (D') associated with oskar mRNPs as a function of the RNA copy number. Error bars represent $95 \%$ confidence intervals, the size of the circles is proportional to the relative abundance of the given sized oskar mRNPs within the entire sample analysed. (E) Relative distribution of oskar mRNPs grouped by RNA content along the first $30 \%$ of anteroposterior axis. In the wild-type control, less than $1 \%$ of large (65+ copies) oskar mRNPs are close to the oocyte anterior (first bin). When Egalitarian is overexpressed, around $10 \%$ of such large oskar mRNPs are present close to the oocyte anterior (first bin, arrow), while the rest of the oocyte has almost identical distribution of oskar mRNPs to control (Fig S5A) (F) Dominance of plus end-directed transport over minus end-directed transport of oskar-MS2(10x) mRNPs ex vivo as a function of normalized MCP-GFP signal in control (brown) and staufen RNAi (red). oskar mRNPs are clustered into small (1-2 normalized units) and large (3 or more units) categories based on MCP-GFP signal intensity. P-values of pairwise Fisher-exact tests are shown. Number of analysed motile oskar mRNPs is indicated. 


\section{Loss of Egalitarian affects dynein function but not association with oskar mRNPs}

Egalitarian functions as an adaptor molecule linking mRNAs to cytoplasmic dynein (Amrute-Nayak and Bullock, 2012; Dienstbier et al., 2009; Navarro et al., 2004). Therefore, the absence of Egalitarian protein on mRNPs in stage 9 oocytes might result in detachment of the entire dynein transport machinery. However, we observed little difference in association of either Bicaudal-D (Fig S4A), of the dynactin subunit p50/dynamitin (Fig S4B), or of Dynein heavy chain (Dhc, Fig S4C) in the nurse cells and the oocyte. The fraction of oskar mRNPs associated with dynein subunits did not change as a function of RNA content in the oocyte (Fig S4D). Notably, the relative amount of the three dynein components associated with oskar mRNPs in the oocyte was approximately double that in the nurse cells (Fig S4E). The amount of Bicaudal-D and p50 associated with the mRNPs in the oocyte was constant, independent of oskar copy number, whereas Dhc association increased as a function of oskar mRNA content (Fig S4E). This might be due to the intrinsic affinity of cytoplasmic dynein for mRNA (Amrute-Nayak and Bullock, 2012; Rom et al., 2007; Sysoev et al., 2016). Increased levels of Egalitarian on oskar mRNPs in absence of Staufen (Fig 3E, E' and S3E, E') or in the presence of excess Egalitarian (Fig 4D, D') could also in principle result in increased recruitment of the dynein motor. However, when we analysed GFP-Dhc association and its relative level on oskar mRNPs, we found no major difference between staufen RNAi, Egalitarian overexpressing and control oocytes (Fig S4F and F'). Similarly, we found no major difference in Bicaudal-D recruitment to oskar mRNPs in the presence and in the absence of Staufen (Fig S4G and G'), indicating that association - most likely the maintenance - of the dynein machinery with the RNPs is largely independent of Egalitarian.

It was previously shown that dynein recruited to mRNA without the dedicated cargo adapter Egalitarian is largely inactive (Amrute-Nayak and Bullock, 2012; McClintock et al., 2018). Our data show that in wild-type oocytes there is a disproportionality among dynein transport machinery components associated with oskar mRNPs. We found little to no cargo adapter Egalitarian - association with even intermediate (4-16+ copy) oskar mRNPs (Figs 3D, D' and S4D and E), although core components of the dynein machinery were present. This suggests that, while the dynein motor remains part of large mRNPs in the oocyte at stage 9, its activity is diminished compared with earlier stages. To see if this is the case, we stratified the ex vivo oskar motility data on the basis of relative MCP-GFP fluorescence intensity (Video S1 and S2). Although the lack of a nurse cell reference in the assay (Little et al., 2015) and the stochastic nature of the MCP-MS2 interaction (Wu et al., 2012) precluded quantification of absolute mRNA copy numbers, classification of relative RNA signal revealed that whereas around $35-40 \%$ of small oskar mRNPs moved towards the microtubule minus ends, fewer than $20 \%$ of larger oskar mRNPs were minus end-directed. Hence, the dominance of plus end-directed runs increases from around 2-fold for small (1-2 relative units), to around 3.5-fold for observed larger (3 or more units) oskar mRNPs (Fig $4 \mathrm{~F})$.

Interestingly, the ex vivo motility analysis revealed that the absence of Staufen results in a major reduction in the percentage of large oskar mRNPs that are motile $(\sim 15 \%$ in control versus $<1 \%$ in stau RNAi ooplasmic extracts ex vivo, Fig $4 \mathrm{~F})$, although it has no effect on the oligomerization state of oskar (Fig S3B). While it is unclear why such large oskar mRNPs fail 
to undergo directed transport, this observation explains the lack of detectable oskar mRNA transport in live staufen mutant oocytes when using the less sensitive confocal live-cell imaging technique (compare Video S2 and S4).

In summary, we found that in stage 9 oocytes, Egalitarian is dispensable for maintaining the association between oskar mRNPs and the dynein machinery. Even more surprisingly, it appears that the maintenance of the core minus end-directed machinery is precisely regulated, independently of the mRNA content of mRNPs. This is in contrast to the RNA binding components, such as Staufen and, in its absence, Egalitarian, which scale with the RNA. However, in all cases the activity of dynein on oskar mRNPs requires the presence of its cargo adapter, Egalitarian.

\section{Egalitarian-dependent staufen mRNA enrichment and Staufen accumulation in the oocyte}

Loss of egalitarian function causes early arrest of oogenesis (Mach and Lehmann, 1997; Schüpbach and Wieschaus, 1989). We noted that in the absence of Egalitarian, only trace amounts of Staufen-GFP accumulated in the undifferentiated oocyte (Fig 5A-C). The normal ooplasmic accumulation of Staufen could in principle result from its transport in association with target mRNAs from the nurse cells into the oocyte. However, this seems unlikely, as we detected no association of Staufen-GFP with its main target, oskar mRNA in the nurse cells (Fig 3A-B'), and both Staufen and Staufen-GFP signal accumulated in the oocyte even in the absence of oskar mRNA (Fig S6A-D). Alternatively, staufen mRNA itself might be transported into and translated within the oocyte. Whereas staufen mRNA was enriched during early oogenesis in small oocytes expressing control RNAi (Fig 5F-G), we observed no such enrichment in egl RNAi egg-chambers (Fig 5E, E' and G). Furthermore, while staufen mRNA did not display any specific localization pattern in wild-type oocytes (Fig $5 \mathrm{H}$ ), upon Egalitarian overexpression staufen mRNA enriched at the anterior pole of the oocyte (Fig $\left.5 \mathrm{H}^{\prime}\right)$. This suggests that, similar to other oocyte-enriched transcripts, such as oskar, gurken and bicoid (Ephrussi et al., 1991; Berleth et al., 1988; Neuman-Silberberg and Schüpbach, 1993; see also Fig 6), staufen mRNA is a target of Egalitarian-dependent transport.

Colocalization analysis revealed that staufen mRNA and Egalitarian-GFP are associated in the germline, and that this association is significantly reduced in the oocyte compared with the nurse cells (Fig 5I). Furthermore, we detected Staufen in association with staufen mRNPs in mid-oogenic stages (Fig 5J), similar to what we observed with oskar mRNPs (Fig 3). Taken together, these data indicate that the Egalitarian-dependent transport of staufen mRNA into the oocyte underlies ooplasmic Staufen enrichment. 
bioRxiv preprint doi: https://doi.org/10.1101/2021.04.24.441269; this version posted April 25, 2021. The copyright holder for this preprint (which was not certified by peer review) is the author/funder, who has granted bioRxiv a license to display the preprint in perpetuity. It is made available under aCC-BY-NC-ND 4.0 International license.
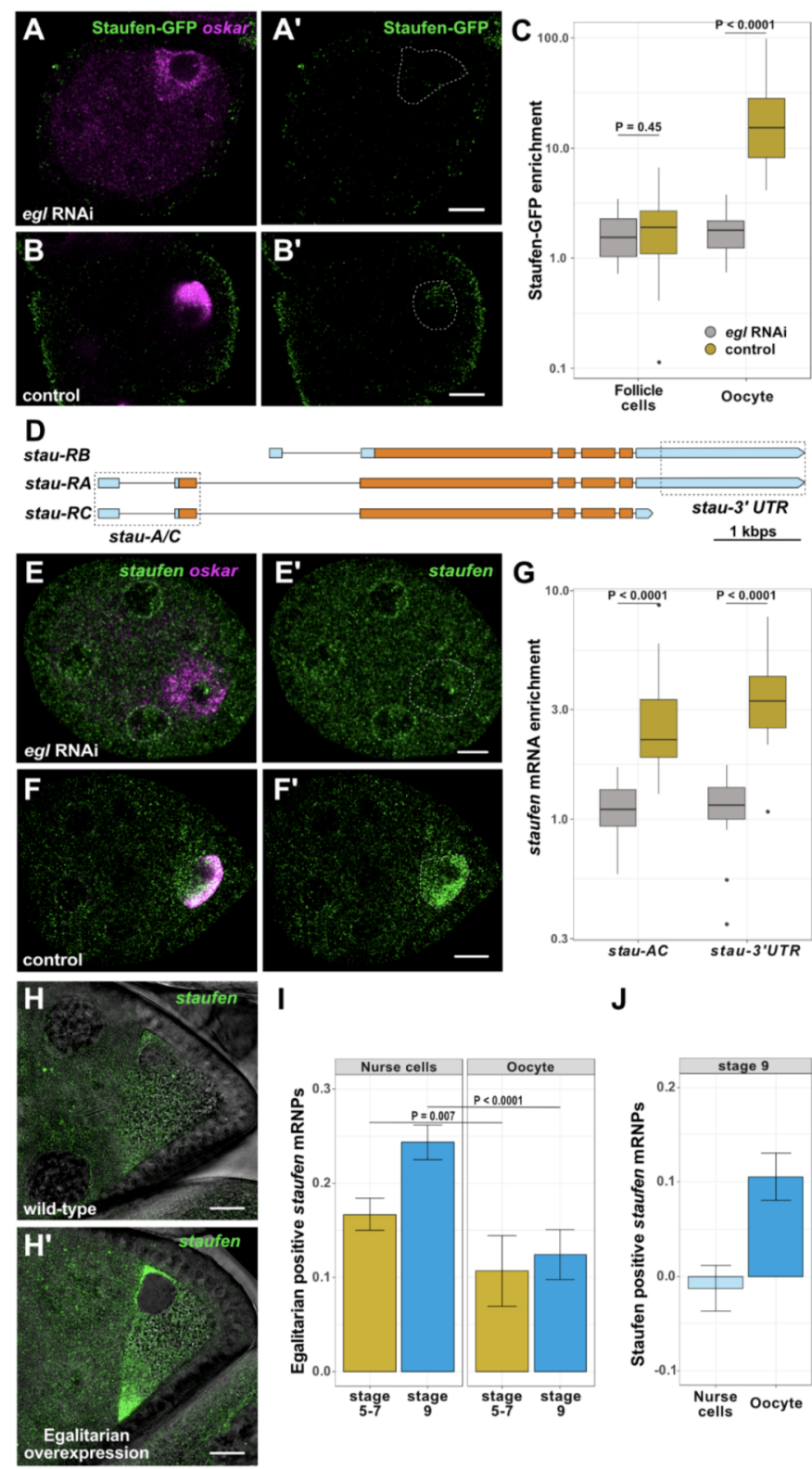

J

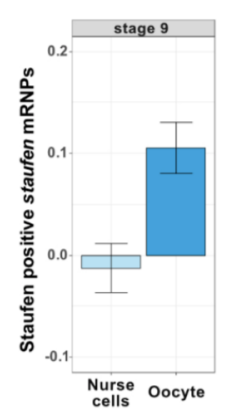

Figure 5: Egalitarian is required for Staufen expression and for ooplasmic enrichment of staufen mRNA.

(A-B') Staufen protein expression detected via Staufen-GFP (green) in early stage egg-chambers expressing egl (A, A') or control RNAi (B, B'). (C) Enrichment of Staufen-GFP signal in oocytes expressing egl (grey) or control RNAi (brown) relative to the sibling nurse cells. Enrichment of Staufen-GFP in somatic follicle cells - which do not express the shRNA is used as a control. P-values of pairwise Student's t-test are shown. (D) The three RNA isoforms encoded by the stau locus. Regions targeted by the stau-A/C and the stau 3'UTR probe sets are indicated by dashed boxes. (E-F') Localization of staufen mRNA, detected by the stau- $A / C$ isoform specific probe set, in early egg-chambers expressing egl RNAi (E, E') or control RNAi ( $F, F^{\prime}$ ). oskar mRNA (magenta A, B, E and F) was used to identify the oocyte, which is indicated by a dashed outline in A', B', E' and F'. (G) Enrichment of staufen mRNA - detected by the stau-A/C isoform specific or the long stau 3'UTR specific probe set. $\left(\mathrm{H}, \mathrm{H}^{\prime}\right)$ Localization of staufen mRNA (green, detected by the stau $\mathrm{A} / \mathrm{C}$ probe set) in wild-type and Egalitarian overexpressing stage 8 oocytes. (I, J) Fraction of staufen RNPs (detected by the stau A/C probe set) associating with (I) Egalitarian in the nurse cells and in the oocyte, and $(\mathrm{J})$ with Staufen in the oocyte. Scale bars represent $10 \mu \mathrm{m}$. 


\section{Localization of bicoid mRNA is regulated by Staufen and Egalitarian}

To test if a regulatory circuit built around Staufen and Egalitarian also acts on other transcripts, we analyzed the localization and composition of the anterior localizing bicoid mRNPs (Fig 6A; Berleth et al., 1988), a known target of Staufen (Ferrandon et al., 1994) and a likely target of Egalitarian (Dienstbier et al., 2009; Ferrandon et al., 1994) . As previously reported, bicoid mRNPs may also contain multiple mRNA copies (Ferrandon et al., 1994; Heber et al., 2019; Trovisco et al., 2016 and Fig 6B and S5B), similar to oskar mRNPs. We found that the relative amount of Staufen-associated bicoid mRNPs is largely independent of RNA copy number (Fig 6B). Staufen amounts on bicoid mRNPs, however, linearly scaled with the bicoid mRNA content, but the degree of scaling was much reduced compared to oskar mRNPs. Notably, Egalitarian association with bicoid mRNPs containing 8+ copies of the mRNA was nearly double that observed for lower copy number bicoid RNPs (Fig 6D'), and also, amounts of cytoplasmic dynein were stable on bicoid mRNPs (Fig S4H, I). These observations suggest that dynein might be more active on larger bicoid mRNPs, which might therefore be expected to localize closer to the anterior pole, where microtubule minus ends are enriched (Parton et al., 2011). To test this hypothesis, we analysed the distribution of bicoid mRNPs along the anteroposterior axis as a function of RNA content (Fig 6E). Small bicoid particles were detected along the entire oocyte length, even in the vicinity of the posterior pole. In contrast, most 8+ RNA copy RNPs were found within the anterior $20 \%$ of the oocyte (Fig 6E).

We next analysed the distribution of bicoid mRNA in stage 9 oocytes. As suggested by the distribution of bicoid mRNPs along the anteroposterior axis (Fig 6E), the center-of-mass of bicoid mRNA was close to the anterior cortex (Fig 6F). In the absence of Staufen, bicoid mRNA shifted significantly closer to the anterior (Fig 6F). In a complementary experiment in which GFP-Staufen was overexpressed, we observed a significant shift in the center of mass of bicoid mRNA signal away from the anterior, towards the center of the oocyte (Fig 6F).

In our Staufen overexpression experiments, we initially tried to express full-length GFP-Staufen under control of female germline specific Gal4 drivers. However, we noted that when GFP-Staufen levels were high, both oskar and bicoid mRNAs were trapped in the nurse cells in large aggregates together with GFP-Staufen (Fig S6F) - similar but larger and more numerous than observed in the case of matTub>GFPStaufen (Schuldt et al., 1998). Aggregate formation appeared to impede the enrichment of the two mRNA species in the developing oocyte (Fig S6F', F"). Furthermore, when we expressed the UASp-GFP-Staufen transgene under control of the oskar-Gal4 driver - which drives expression earlier than matTub-Gal4 - most oocytes failed to progress beyond stage 6 of oogenesis and showed a fragmented karyosome phenotype (Fig S6G; Jenny et al. 2006), characteristic of the absence of oskar mRNA. Nuclei of the few oocytes developing to mid-oogenesis invariably failed to migrate to the anterior (Fig $\mathrm{S} 6 \mathrm{H}$ ). This indicates a failure in repolarisation of the microtubule cytoskeleton, at least partially due to defective dynein mediated gurken mRNA localization. Such mislocalization of gurken mRNA and the consequent mis-polarisation of the oocyte cytoskeleton has been reported upon knock-down of egalitarian mRNA (Sanghavi et al., 2016). 
bioRxiv preprint doi: https://doi.org/10.1101/2021.04.24.441269; this version posted April 25, 2021. The copyright holder for this preprint (which was not certified by peer review) is the author/funder, who has granted bioRxiv a license to display the preprint in perpetuity. It is made available under aCC-BY-NC-ND 4.0 International license.

Taken together, these findings show that similar to oskar, minus end-directed transport and localization of bicoid mRNA is regulated by a balance between Staufen and Egalitarian. In the case of bicoid the Egalitarian:Staufen balance prevents inactivation of the dynein machinery, leading to anterior localization of the mRNA. In the case of oskar, Staufen dominance on the mRNPs displaces Egalitarian, downregulating dynein activity, and allowing kinesin dependent transport of the mRNA to the posterior pole.
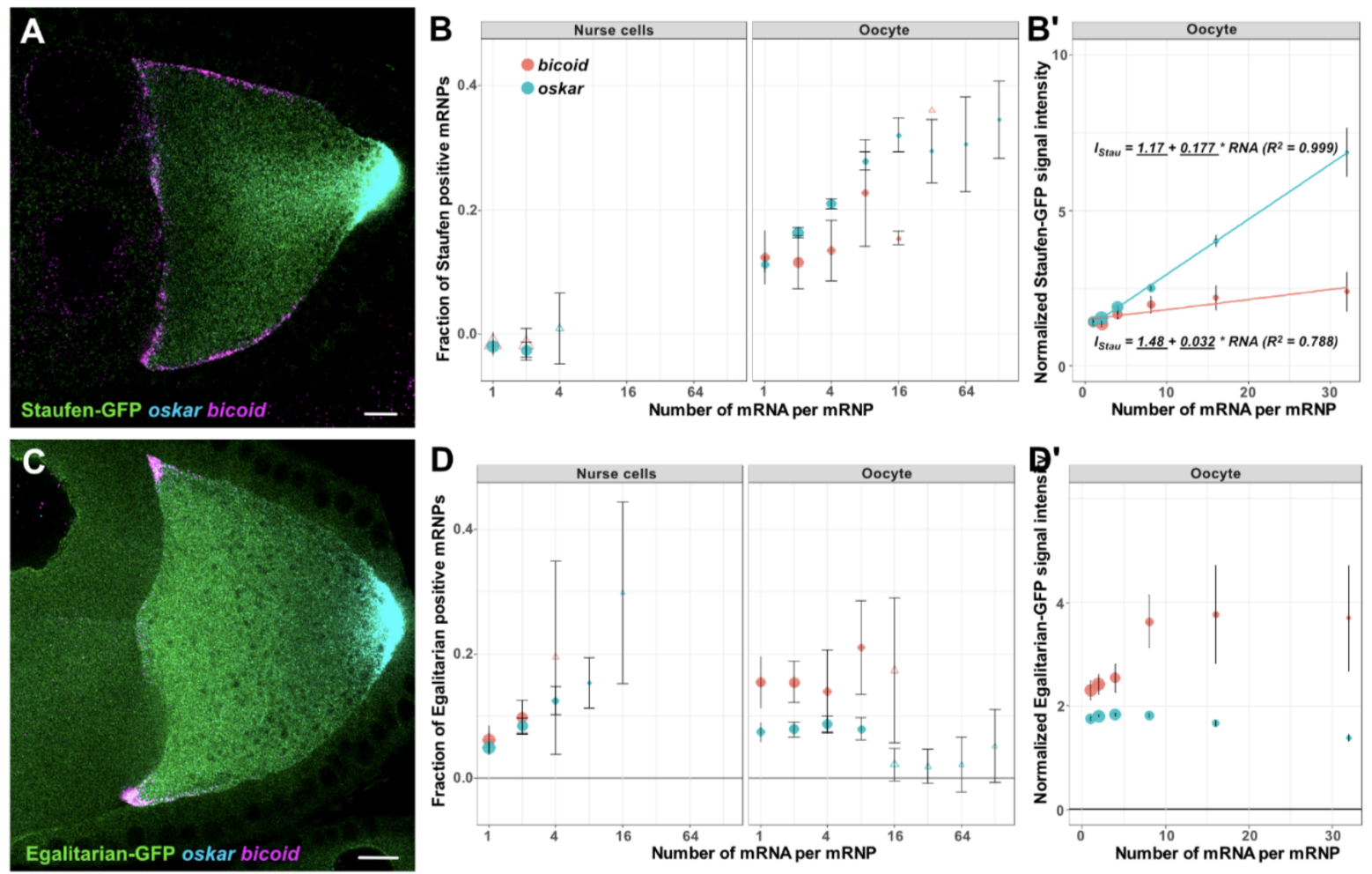

E

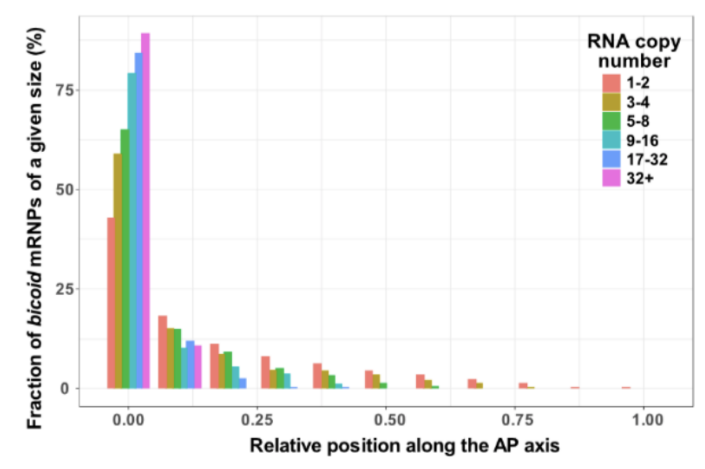

$\mathbf{F}$

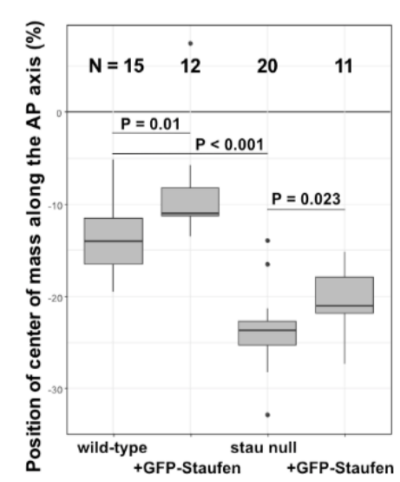

Figure 6:Association of bicoid mRNPs with Staufen and Egalitarian.

(A, C) Localization of bicoid (magenta) and oskar (cyan) mRNAs relative to Staufen (A) and Egalitarian (C) within stage 9 egg-chambers. Scale bars represent $10 \mu \mathrm{m}$. (B, D) Fraction of bicoid (red) and oskar (cyan) mRNPs colocalizing with Staufen-GFP (B) or Egalitarian-GFP (D). (B', D') Normalized GFP signal intensity of Staufen-GFP (B') or Egalitarian-GFP (D') colocalizing with bicoid (red) or oskar (cyan) mRNPs. In these experiments a single copy of Staufen-GFP or two copies of Egalitarian GFP were expressed in wild-type background. (B') Fitted linear models of the correlation between Staufen-GFP signal intensity and the mRNA copy number are shown as solid lines and equations (top - oskar mRNPs, bottom - bicoid mRNPs). Underscored parameters of the models are significantly different from zero $(p<0.05)$. The slopes of the two fitted models are significantly different ( $p<0.0001$, ANOVA). (B, B') Egg-chambers expressing one copy of Staufen-GFP in the presence of two wild-type alleles of staufen. (D, D') Egg-chambers expressing two copies 
of Egalitarian-GFP in the presence of two wild-type alleles of egalitarian. (B, B', D, D') Error bars show the $95 \%$ confidence interval of the mean. (E) Distribution of bicoid mRNPs sorted by their RNA copy numbers (see color scale) along the AP axis in wild-type. (F) The position of the center of mass of bicoid mRNA along the AP axis in fixed stage 9 oocytes in the presence, in the absence, and in presence of excess of Staufen. Zero (0) indicates the geometric center of the oocyte, the anterior pole is around $-42 \%$. Number of analysed oocytes and $\mathrm{P}$-values of pairwise Mann-Whitney $\mathrm{U}$ tests are indicated.

\section{Discussion}

As shown previously, the activity of motor molecules is essential for establishing proper localization of RNA molecules which in turn underlies spatiotemporal restriction of RNA associated (coding) function (Abouward and Schiavo, 2021; Martin and Ephrussi, 2009; Mofatteh and Bullock, 2017; St Johnston, 2005). While not restricted to cells with enlarged dimensions, such as in neurons and in oocytes, the importance of this motor activity becomes apparent in these cell types. Our data on the in situ interaction of two RNA binding proteins, Egalitarian and Staufen with their target RNA molecules shows that the regulation of RNA localization is - at least in part - based on RNA localization: Egalitarian, which recruits the minus end-directed dynein machinery to mRNPs is responsible for the enrichment of staufen mRNA in the developing oocyte. The consequently increasing levels of ooplasmic Staufen appear to interfere with the association of Egalitarian with oskar and staufen mRNPs, preventing their anterior accumulation in wild-type oocytes. For bicoid mRNPs, such interference is not observed under normal conditions, despite Staufen binding to bicoid mRNA. This might be due to a reduced affinity and/or different mode of binding of Staufen to bicoid as compared to oskar mRNPs. Nevertheless, overexpression of Staufen results in a dynein-inhibitory phenotype in the process of bicoid localization - and likely that of other mRNAs - indicating that this regulation of RNP transport and localization acts on multiple mRNA species. Also, as indicated by the strong phenotypes caused by Staufen misexpression, the staufen mRNA localization component of this regulatory mechanism is essential to restrict the regulatory action to the oocyte compartment, allowing uninterrupted transport of RNPs from the nurse cells into the oocyte.

Our data support a simple model of affinity-mediated competition between the two RNA binding proteins, Egalitarian and Staufen: when unimpeded, the degree of association of both proteins appears to scale with the RNA content of oskar mRNPs. During early oogenesis, when Staufen levels are low, amounts of Egalitarian scale with oskar RNA content. During stage 9, however, this scaling is lost in the oocyte and the relative amount of Egalitarian on oskar mRNPs drops to about half of the amount at earlier stages. Although with our intensity-based colocalization assay, we are unable to provide the absolute numbers of molecules in the RNPs, it is tempting to speculate that this drop in Egalitarian amounts reflects a shift from motion-promoting cargo binding - mediated by two copies of Egalitarian as observed in vitro (McClintock et al., 2018) - towards the auto-inhibited state of Bicaudal-D and the dynein machinery (Liu et al., 2013). Larger bicoid mRNPs, on the other hand, contain double the amount of Egalitarian in stage 9 oocytes. Although the degree of association of the other components of the dynein machinery does not seem to vary considerably with the RNA content of either of oskar and bicoid RNPs in stage 9 oocytes, the changes in their Egalitarian content correlate well with their motility and localization in the 
oocyte: larger bicoid mRNPs close to the anterior and larger oskar mRNPs close to the posterior pole.

While dynein association does not appear to scale with the oskar or bicoid RNA content in RNPs, within the oocyte the relative amounts of the dynein machinery components examined increases for both RNPs. This could reflect an ongoing assembly of the dynein motor complex on RNPs in the nurse cells, while only RNPs with a mature dynein machinery can reach the oocyte. Interestingly, however, increased amounts of the cargo adapter, Egalitarian on oskar - in the absence of Staufen or when Egalitarian is overexpressed - did not result in increased dynein association with the RNPs, shedding light on a regulatory mechanism that controls loading of the minus end-directed motor. Given that even a single dynein molecule - let alone the two, normally recruited by a single Bicaudal-D (Sladewski et al., 2018) - can efficiently move cargo much larger than a few tens of RNA molecules and their associated proteins (Akhmanova and Hammer, 2010), this regulation ensures an ergonomic distribution of the transporter amongst its cargoes. Although details of the molecular mechanism remain to be determined, it transpires from our data that this regulatory mechanism controls the recruitment of Bicaudal-D. The amounts of Bicaudal-D recruited to oskar are stable, independent of the RNA content of the RNPs. For most oskar mRNPs, the relative levels of the motor subunit, Dhc, are about double that of Bicaudal-D, consistent with the one-to-two stoichiometry of the two proteins observed in functional transport complexes in vitro (McClintock et al., 2018; Sladewski et al., 2018) . However, larger oskar mRNPs display higher Dhc content, independent of Egalitarian and Bicaudal-D (Fig. S4E), reflecting the affinity of this molecule for RNA observed in vitro (Amrute-Nayak and Bullock, 2012). As such, these Dhc molecules are presumed to be transport incompetent, passively transported by kinesin-1 to the posterior pole (Williams et al., 2014).

The Drosophila Staufen protein and its mammalian orthologs, mStau1 and mStau2 have been shown to regulate not only the transport (Bauer et al., 2019; Zimyanin et al., 2008), but also the expression of their RNA targets (Heraud-Farlow et al., 2013; Micklem et al., 2000). The latter is achieved through Staufen mediated RNA decay (Kim et al., 2005); (Park et al., 2013) or facilitation of protein expression, as reported for Staufen in regulating Oskar protein synthesis during Drosophila oogenesis (Micklem et al., 2000 + this manuscript). As the effect of these types of regulation can be long-lasting, tight spatiotemporal control of the processes is essential. As we have shown in the Drosophila germline, this could be achieved by staufen RNA localization.

The same RNA localization process ensures that Staufen protein recruited to oskar mRNPs in the oocyte inactivates the dynein machinery. This ensures that oskar mRNA levels remain low at the anterior, preventing ectopic Staufen-promoted accumulation of Oskar protein. By analogy, given that the function of Staufen is largely conserved (Heber et al., 2019), it is plausible that the described feed-forward loop established by staufen RNA localization is a paradigm of an evolutionarily conserved regulation that controls target RNA localization and expression in other tissues and organisms.

\section{Methods}




\section{Fly strains}

To knock down staufen and egalitarian RNA levels, we used the P\{TRiP.GL01531\} (

FBal0281234) and the P\{TRiP.HM05180\} (FBal0240309) transgenic lines. TRiP line against the $w$ gene (P\{TRiP.GL00094\} - FBal0262579) was used as a negative control. The following mutant lines were used to disrupt or modify gene function: stau[D3] (FBal0016165) and stau[R9] (FBal0032815) alleles in heterozygous combination; eg/[1] (FBal0003574) and eg/[2] (FBal0003575); BicD[1] (FBal0001140) and BicD[2] (FBal0001141); osk[A87] (FBal0141009) in combination with Df(3R)p-XT103 (FBab0002842) to remove oskar mRNA from egg-chambers. w[1118] (FBal0018186) was used as the wild-type control.

To overexpress Staufen, we used the aTub67C:GFPm6-Staufen (FBal0091177), aTub67C:RFP-Staufen (Zimyanin et al., 2008) transgenic lines and a P\{UASp-Staufen\} transgene inserted onto the $3^{\text {rd }}$ chromosome (kind gift of $F$. Besse)

To overexpress Egalitarian protein, we used the $\mathrm{P}\{\mathrm{UASp}$-egl.B $\}$ transgene (FBtp0022425) inserted on the $\mathrm{X}$ or the $3^{\text {rd }}$ chromosome (kind gift of $\mathrm{S}$. Bullock).

To label proteins of interest, we used the following fluorescently tagged reporter lines: P $\{$ Staufen-GFP $\}$ inserted on the $3^{\text {rd }}$ chromosome, expressing Staufen-GFP under control of the endogenous stau promoter (kind gift of F. Besse); P\{tub-egl.EGFP\} (FBtp0041299) inserted on the $3^{\text {rd }}$ chromosome, driving expression of Egalitarian-GFP under the control of the ubiquitous tubulin promoter (kind gift of S. Bullock); P\{UASp-BicD.eGFP (FBtp0069955) and P\{UAS-DCTN2-p50::GFP (FBtp0016940) transgenic insertions to label Bicaudal-D and Dynamitin, respectively. To drive the expression of the TRiP RNAi lines and other UASp constructs in the female germline, one copy of $\mathrm{P}\{$ oskar-Gal4\} (FBtp0083699) was used. For moderate overexpression of UASp-GFP-Staufen, we used one copy of P\{mata4-GAL-VP16\} (FBtp0009293)

The Dhc locus was tagged with the EmeraldGFP coding sequence to generate a GFP-Dhc expressing fly line according to protocols of the flyCRISPR website ( (Gratz et al., 2013) O'Connor-Giles et al., 2014; https://flycrispr.org/). The locus was targeted using CRISPR/Cas9 and the following a guide RNA (5' GAGTCACCCATGTCCCACAA AGG). The introduced double-stranded break was repaired by homologous recombination using an in-frame EmeraldGFP coding sequence flanked by two $~ 700$ bp long homology arms targeting around the Dhc64C translation start codon. F1 generation embryos were screened for GFP fluorescence to identify individuals with a modified genome. Flies homozygous for GFP-Dhc are viable and fertile. All stocks were raised on normal cornmeal agar at $25^{\circ} \mathrm{C}$, and females were fed a high protein diet overnight before harvesting their ovaries.

\section{RNA co-immunoprecipitation (RIP) from ovarian lysate}

RIP was carried out as described in (Gáspár et al., 2017). Briefly, ovaries from 50 flies were dissected in Brb80 (80 mM PIPES, $1 \mathrm{mM} \mathrm{MgCl}, 1 \mathrm{mM}$ EGTA, $\mathrm{pH}$ 6.8) and lysed in Pre-XL buffer (20mM Tris-Cl, $150 \mathrm{mM} \mathrm{KCl}, 4 \mathrm{mM} \mathrm{MgCl}_{2}$, 2xPIC, $1 \mathrm{mM} \mathrm{PMSF,} \mathrm{pH7.5;} \mathrm{supplemented}$ with $40 \mathrm{U}$ of RiboLock RNase Inhibitor per $100 \mu \mathrm{L}$ lysate). Ovaries were ground using a pestle and centrifuged for $1 \mathrm{~min}$ at $500 \times \mathrm{g}$. The supernatant was extracted and crosslinked at $0.3 \mathrm{~J} / \mathrm{cm}^{2}$. The lysate was equalized with 1 volume of Pre-XL buffer, 1 volume of RIPA (10 $\mathrm{mM}$ Tris/Cl pH 7.5; $150 \mathrm{mM} \mathrm{NaCl} ; 0,5 \mathrm{mM}$ EDTA; 0,1\% SDS; $1 \%$ Triton $\mathrm{X}-100 ; 1 \%$ Deoxycholate, $0.09 \%$ Na-Azide) buffer and 8 volumes of low salt buffer (20mM Tris-Cl, $150 \mathrm{mM} \mathrm{KCl}, 0.5 \mathrm{mM}$ EDTA, 1mM PMSF). GFP-Trap®_MA beads were washed with low salt 
buffer and blocked for 60 mins at room temperature in Casein Blocking Buffer (Sigma-Aldrich) supplemented with $50 \mu \mathrm{g} / \mathrm{mL}$ Heparin. Lysate was incubated with beads for 90 minutes at $4^{\circ} \mathrm{C}$. The beads were then washed six times with high salt buffer $(20 \mathrm{mM}$ Tris-Cl, $500 \mathrm{mM} \mathrm{NaCl}, 1 \mathrm{mM}$ EDTA, 0.1\%SDS, 0.5mM DTT, 1xPIC, 1mM PMSF) and twice with PBT (PBS + $0.1 \%$ Triton). Endogenous RNA cross-linked to bait protein was recovered from the beads using the QuickRNA Microprep Kit (Zymo Research). Complementary DNA was synthesized using the SuperScript III First-Strand Synthesis kit (Invitrogen) and used as template for PCR using oskar and bicoid primers.

\section{Single molecule fluorescent hybridization (smFISH)}

Single molecule FISH was carried out as described previously (Gaspar et al., 2017; Gáspár et al., 2017; Heber et al., 2019). Briefly, ssDNA oligonucleotides complementary to oskar (Gaspar et al., 2017), bicoid (Heber et al., 2019) and staufen mRNAs (Table S1) were mixed and labelled with Atto532, Atto565 or Atto633 according to the protocol described in Gaspar et al., 2017.

Drosophila ovaries expressing fluorescent reporter transgenes were dissected in $2 \% \mathrm{v} / \mathrm{v}$ PFA, $0.05 \%$ Triton $X-100$ in PBS and fixed for $20 \mathrm{~min}$. The fixative was removed by two 5 minute washes in PBT (PBS + 0.1\% (v/v) Triton X-100, $\mathrm{pH} 7.4)$. Ovaries were pre-hybridized in $200 \mu \mathrm{L} 2 \times \mathrm{HYBEC}(300 \mathrm{mM} \mathrm{NaCl}, 30 \mathrm{mM}$ sodium citrate $\mathrm{pH} 7.0,15 \%(\mathrm{v} / \mathrm{v})$ ethylene carbonate, $1 \mathrm{mM}$ EDTA, $50 \mu \mathrm{g}$ per $\mathrm{mL}$ heparin, $100 \mu \mathrm{g}$ per $\mathrm{mL}$ salmon sperm DNA, 1\% (v/v) Triton $\mathrm{X}-100)$ for $10 \mathrm{~min}$ at $42^{\circ} \mathrm{C}$. Meanwhile, the $50 \mu \mathrm{L}$ probe mixture $(5 \mathrm{nM}$ per individual oligonucleotide) was prepared and pre-warmed to hybridisation temperature. After 10 minutes of pre-hybridization, the probe mix was mixed into the pre-hybridization mixture. After 2 hours of hybridization at $42^{\circ} \mathrm{C}$, the unbound probe molecules were washed out of the specimen by two washes in pre-warmed HYBEC and a final wash in PBT at room temperature. To boost signal intensity for the protein enrichment analysis of Staufen-GFP in early egg-chambers, we incubated the ovaries in GFP-Booster (Chromotek) diluted 1:2000 in PBT for 1 hour, then washed the sample three times for 10 minutes in PBT. Ovaries were mounted in Vectashield and processed for smFISH analysis.

\section{Microscopy and image analysis}

All imaging was carried out on a Leica TCS SP8 confocal laser scanning microscope using a $20 \mathrm{x}$ dry (NA $=0.75$ ) objective for imaging the RNA distribution in the oocytes and a $63 \mathrm{x}$ oil immersion (NA = 1.4) objective for analysis of RNA or Staufen-GFP protein enrichment in early oocytes and for colocalization analysis between RNPs and the fluorescently labelled Staufen and Egalitarian proteins.

\section{RNA distribution analysis}

Analysis of oskar and bicoid mRNA distribution was carried out as described in (Gaspar et al., 2014; Gáspár et al., 2017; Heber et al., 2019). Briefly, we manually defined the outlines of the oocytes and their anteroposterior (AP) axis, Using a custom-made ImageJ plug-in, the smFISH signal was redistributed into a $100 \times 100$ matrix. Each column of the matrix 
represents the relative amount of signal found under $1 \%$ of the AP axis length, with anterior on the left (column 1) and posterior on the right (column 100). The matrices from different oocytes of the same genotype and stage were averaged to obtain an average view RNA localization. The center-of-mass (relative to the geometric center of the oocyte) was determined and compared statistically using a Kruskal-Wallis test followed by pairwise Mann-Whitney U test against the control.

\section{RNA and protein enrichment analysis}

The boundaries of the somatic follicle cells, nurse cells and oocyte were manually defined, and the fluorescence intensity of smFISH or GFP signal in these compartments was measured by ImageJ. The extent of enrichment of RNA and protein in the somatic follicle cells and the oocyte was obtained by normalizing the measured fluorescence intensity values to the corresponding values obtained for the nurse cells.

\section{Colocalization analysis between the mRNPs and fluorescent reporters}

Analysis was carried out as described in (Gáspár et al., 2017; Heber et al., 2019). Briefly, images for colocalization analysis were deconvolved using Huygens Essential and segmented using a custom ImageJ plug-in. Nearest-neighbor pairs between mRNPs and fluorescent reporters were identified, their position and signal intensities were extracted from the nurse cell and oocyte compartments, excluding any nuclear areas in the field of view. Number of mRNA molecules in an mRNP and normalisation of the fluorescent reporter signal was carried out by fitting multiple Gaussian functions to the corresponding signal intensity distributions taken from the nurse cells using the mixtools package in $\mathrm{R}$ (Benaglia et al., 2009; R Core Team, 2014). The $\mu$ value of Gaussian fit that described the largest portion of the distribution in the nurse cells (almost the lowest value of all fitted $\mu$ values) was taken as the signal intensity of a unit (for mRNPs the intensity of a signal mRNA molecule). These unit values were used to normalise raw signal intensities. RNPs were clustered based on this normalized intensity under the following rule: [2i:2i+1], $i \in[0: 8]$, i.e., 1, 2:3, 4:7, 8:15, etc. The observed nearest-neighbor colocalization frequencies were computed for each cluster and were compared to the expected colocalization frequencies (governed by the object-densities, determined in randomized object localizations). Similarly, the mean, normalised intensity of colocalizing fluorescent reporter molecules was calculated for each cluster. Correlation between RNA content and the normalised mean fluorescent reporter intensity was tested and compared using least-squares means analysis in R (Lenth, 2016).

\section{Statistical analysis}

All statistical analyses performed are indicated in the respective figure legend. All analysis was done using $\mathrm{R}$ ( $\mathrm{R}$ Core Team, 2014) and RStudio (www.rstudio.com). All graphs were plotted by the ggplot2 library in R (Wickham, 2016).

\section{Acknowledgements}


We thank the EMBL Advanced Light Microscopy and Gene Core Facilities for their support. We acknowledge Alessandra Reversi (EMBL Drosophila Injection Service) for fly transgenesis. We thank Florence Besse and Simon Bullock for Drosophila strains. We thank Simone Heber for critical comments on the manuscript. This work and L.J.P. were supported by DFG-FOR 2333 grants EP 37/2-1 and EP 37/4-1 from the Deutsche Forschungsgemeinschaft (Germany) to A. E. A.E. acknowledges funding from the EMBL.

\section{Author contributions}

I.G. designed the experiments. I.G. and L.J.P carried out the experiments and analysed the data. I.G., L.J.P and A.E. discussed the data and wrote the manuscript. 
bioRxiv preprint doi: https://doi.org/10.1101/2021.04.24.441269; this version posted April 25, 2021. The copyright holder for this preprint

(which was not certified by peer review) is the author/funder, who has granted bioRxiv a license to display the preprint in perpetuity. It is made available under aCC-BY-NC-ND 4.0 International license.

\section{Supplementary Material}

A
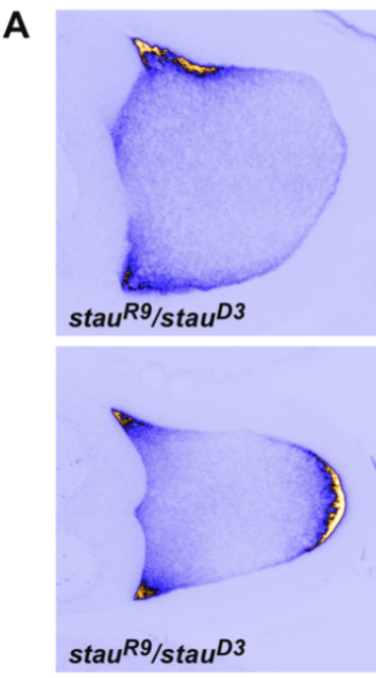

$\mathbf{G}$

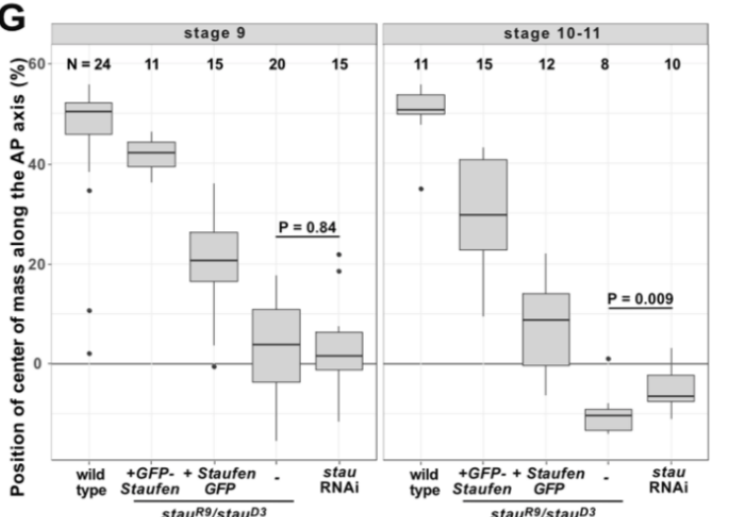

H

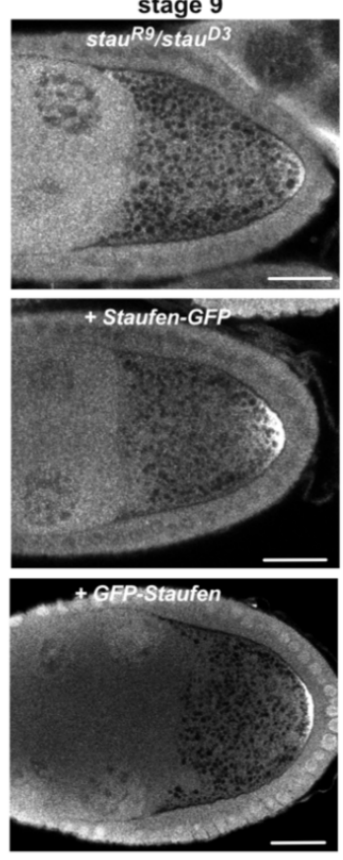

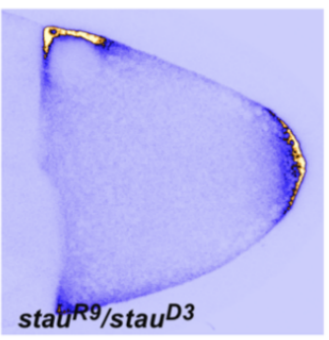

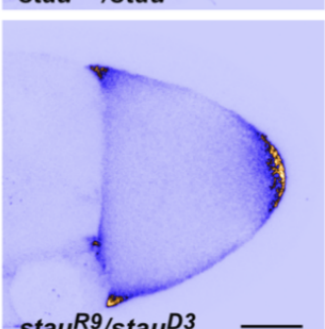

stage 10-11
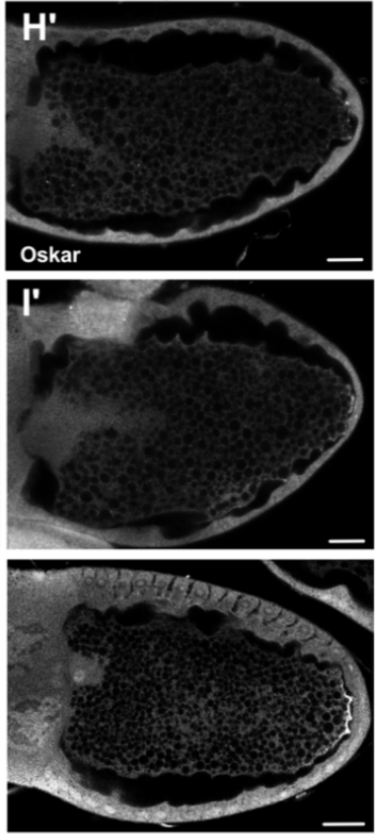

stage 9

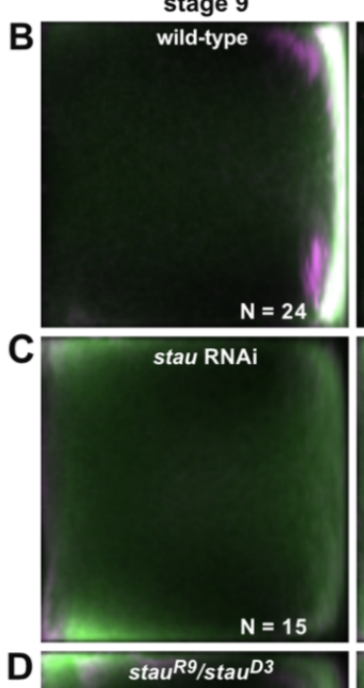

stage $10-11$
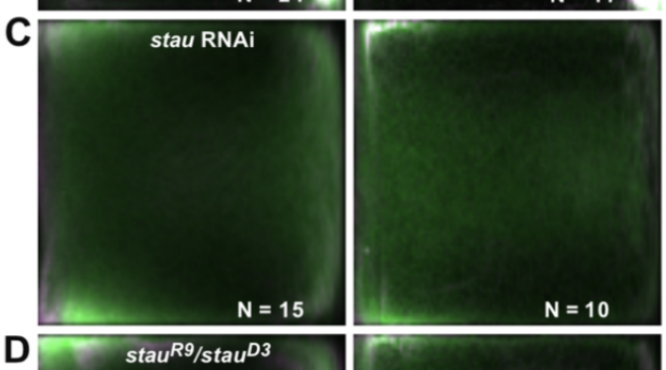

$\mathbf{E}$
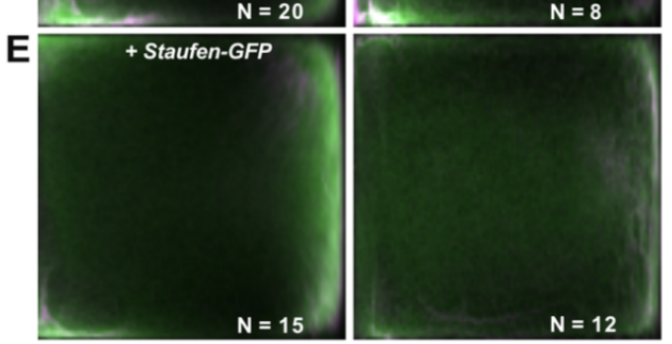

$\mathbf{F}$

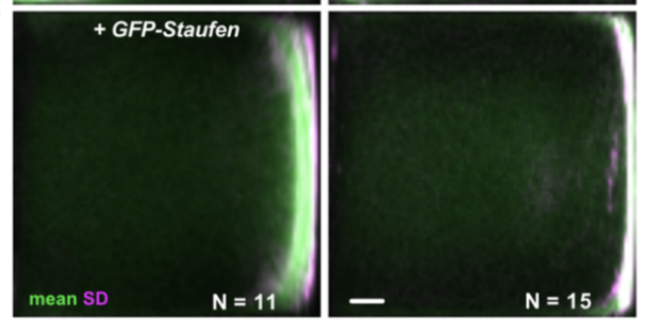

I

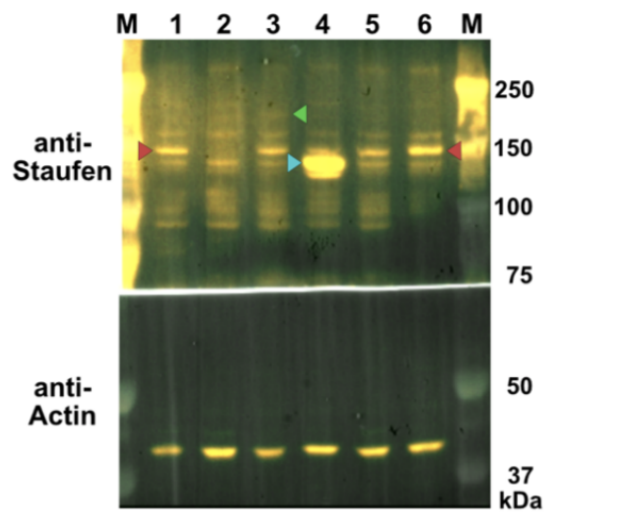

Figure S1: Expression and effect of the different Staufen transgenes on oskar mRNA localization.

(A) Examples of observed oskar RNA localization phenotypes in stage $9 \mathrm{stau} / \mathrm{Rg} / \mathrm{stau}^{D 3}$ mutant oocytes. (B-F) Average distribution of oskar mRNA (green) and variability of the distribution (SD, magenta) in stage 
bioRxiv preprint doi: https://doi.org/10.1101/2021.04.24.441269; this version posted April 25, 2021. The copyright holder for this preprint (which was not certified by peer review) is the author/funder, who has granted bioRxiv a license to display the preprint in perpetuity. It is made available under aCC-BY-NC-ND 4.0 International license.

9 and stage 10-11 oocytes. Numbers indicate the number of oocytes analysed for each condition, scale bar represents $10 \%$ of anteroposterior axis length. $(G)$ Position of the oskar center-of-mass along the AP axis in stage 9 and stage 10-11 oocytes for each condition. 0 represents the geometric center of the oocyte, the posterior pole is located at around $58 \%$. $(\mathrm{H})$ Expression of Oskar protein in oocytes lacking Staufen, rescued by the Staufen-GFP and GFP-Staufen transgenes. (I) Western blot detection of Staufen in wild-type (lane 1), stau ${ }^{R 9} / \operatorname{stau}^{D 3}$ (2), Staufen-GFP (3), GFP-Staufen (4), staufen RNAi (5) and control RNAi (6) ovarian lysates. (A, H) Scale bars represent 20 microns. Note that the distribution of oskar in $\operatorname{stau}^{R 9} / \mathrm{stau}^{D 3}$ and in staufen RNAi oocytes is nearly identical (C, D and G), in spite of residual presence of Staufen in Staufen RNAi ovarian lysates (I, lanes 5 and 6). The Staufen overexpressing GFP-Staufen (I, lane 4) transgene largely rescues the oskar mislocalization ( $F$ and $G$ ) and Oskar protein expression defect $(\mathrm{H})$ observed in the absence of Staufen. The Staufen-GFP transgene, expressed at low levels (I, lane 3), rescues oskar RNA localization during stage 9, but the RNA is not maintained at the posterior during stages 10-11 ( $E$ and $G$ ), most likely due to inefficient expression of Oskar protein at the posterior $(H)$, which is essential for oskar mRNA anchoring at the oocyte posterior during the later stages (Vanzo and Ephrussi, 2002). 
bioRxiv preprint doi: https://doi.org/10.1101/2021.04.24.441269; this version posted April 25, 2021. The copyright holder for this preprint (which was not certified by peer review) is the author/funder, who has granted bioRxiv a license to display the preprint in perpetuity. It is made available under aCC-BY-NC-ND 4.0 International license.
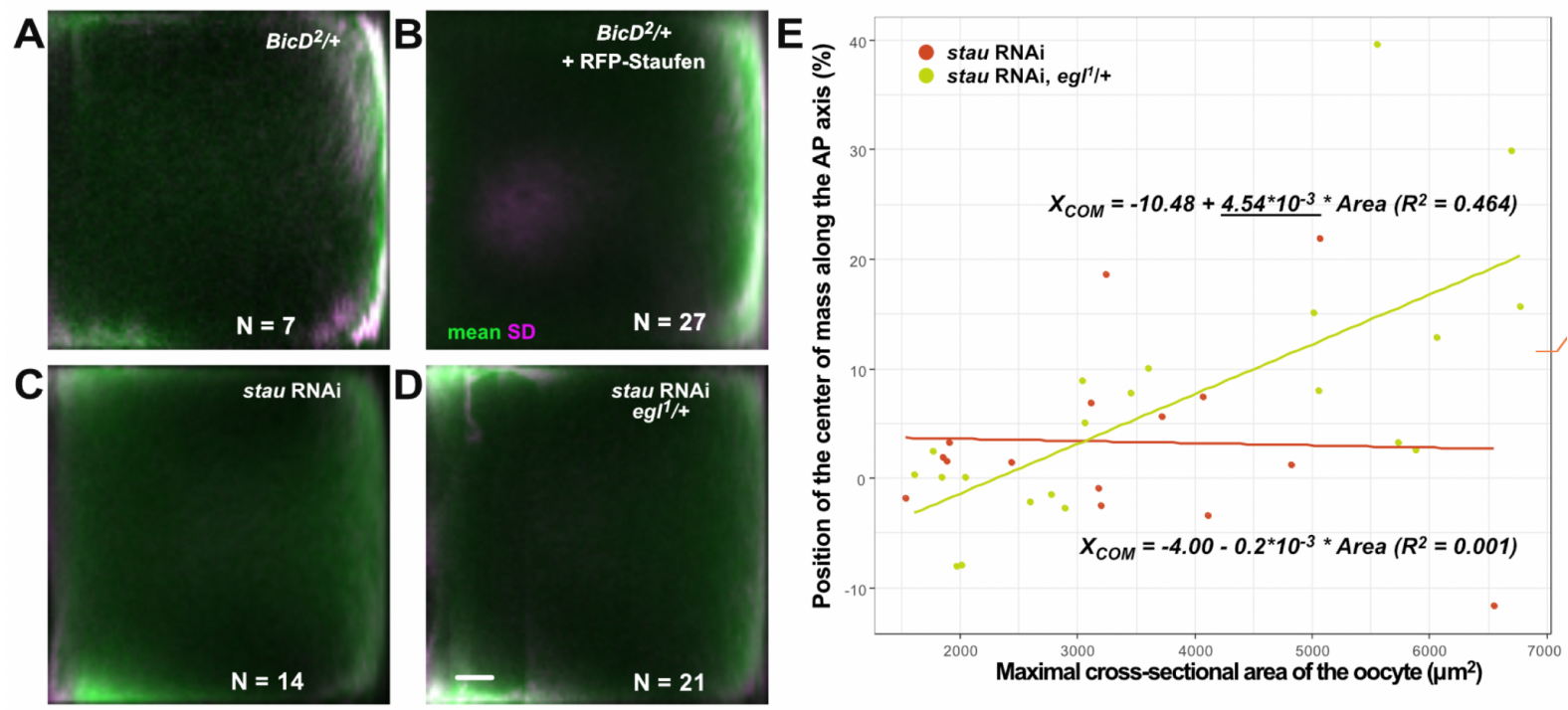

Figure S2: Rescue of oskar mislocalization

(A-D) Average distribution of oskar mRNA (green) and variability of the distribution (SD, magenta) in stage 9 oocytes of the indicated genotypes. (E) Distribution of the observed oskar center-of-mass in stage 9 staufen RNAi oocytes in the presence of two (red) or one (yellow) functional copies of egalitarian, as a function of oocyte size, which is used as a proxy for developmental time. Solid lines show the best linear fits to the data. The equation and the square of the goodness-of-fit $\left(R^{2}\right)$ are indicated. Note that there is no significant linear correlation between oocyte size (developmental age) and the position of the center-of-mass in stau RNAi (red), indicating a rather static oskar mislocalization phenotype. There is a moderate correlation with a significant slope (underlined) when a copy of egalitarian is removed (yellow), indicating progressive posterior-ward localization of oskar mRNA during stage 9. 
bioRxiv preprint doi: https://doi.org/10.1101/2021.04.24.441269; this version posted April 25, 2021. The copyright holder for this preprint (which was not certified by peer review) is the author/funder, who has granted bioRxiv a license to display the preprint in perpetuity. It is made available under aCC-BY-NC-ND 4.0 International license.
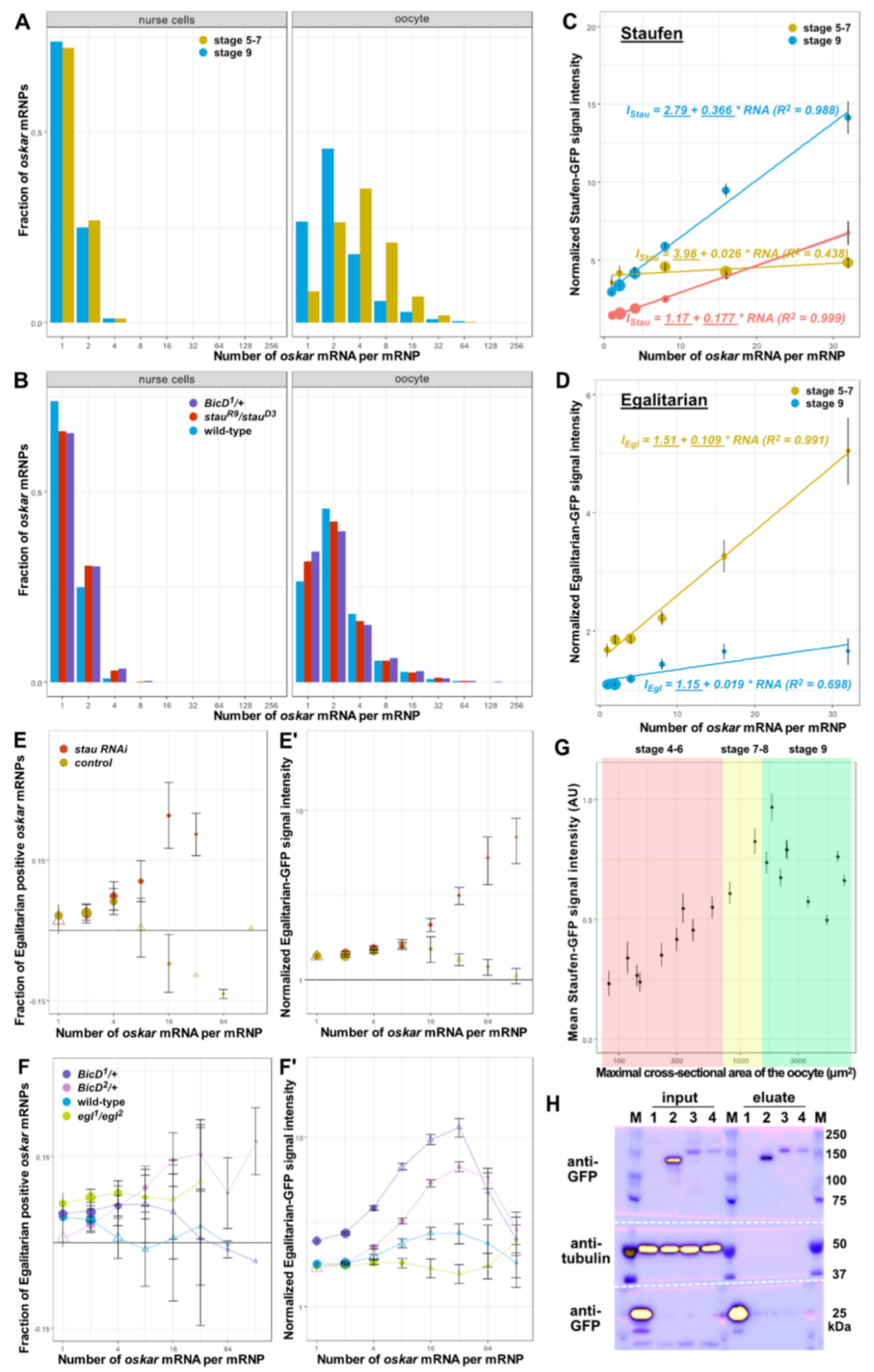

Figure S3: Association of Staufen and Egalitarian with oskar mRNPs

(A, B) Distribution of the RNA content of oskar mRNPs in nurse cells and wild-type oocytes (A) during stages 5-7 (yellow) and stage 9 (blue) of oogenesis, and $(B)$ in the absence of Staufen (red) and in the presence of the dominant Bic ${ }^{1}$ mutant allele (purple). (A) In the nurse cells, the vast majority of oskar mRNPs contain 1-2 copies of the RNA, as reported previously (Little et al., 2015). RNA content of oskar RNPs increases in the oocytes: during stages 5-7 most appear to contain 4+ copies of the RNA; this value decreases to 2+ copies during the phase of posterior localization of oskar (stage 9, also see Little et al., 2015). (C, D) Normalized Staufen-GFP (B') or Egalitarian-GFP (D', E') signal intensity as function of the mRNA content of oskar mRNPs during stages 5-7 (yellow) and stage 9 (blue). (C) Staufen-GFP signal intensity in the complete absence (yellow and blue) and in the presence (red) of wild-type levels of 
bioRxiv preprint doi: https://doi.org/10.1101/2021.04.24.441269; this version posted April 25, 2021. The copyright holder for this preprint (which was not certified by peer review) is the author/funder, who has granted bioRxiv a license to display the preprint in perpetuity. It is made available under aCC-BY-NC-ND 4.0 International license.

endogenous, unlabelled Staufen. (C, D) Fitted linear models of the correlation between (C) Staufen-GFP and (D) Egalitarian-GFP signal intensity and oskar mRNA copy number are shown as solid lines and equations (top - stages 5-7, bottom - stage 9). Underscored parameters of the models are significantly different from zero $(p<0.05)$. The slopes of the two fitted models are significantly different $(p<0.0001$, ANOVA). (E-F') Association of Egalitarian-GFP with oskar mRNPs in oocytes expressing (E, E') staufen RNAi (red), control RNAi (brown), (F, F') BicD $D^{1}$ (purple) or $B i c D^{2}$ (pink) alleles. (E) Note that knock-down of Staufen results in an almost identical retention of Egalitarian on oskar mRNPs as observed in complete absence of Staufen protein (Fig 3E, E'). (D-F') Egg-chambers expressed a single copy of Egalitarian-GFP in the presence of two endogenous wild-type egalitarian alleles, except in the case of the rescued egalitarian mutants ( $\mathrm{F}, \mathrm{eg} \mathrm{I}^{1} / \mathrm{eg} \mathrm{l}^{2}$, green). Although in this case we observed a slightly elevated fraction of Egalitarian positive mRNPs, larger mRNPs containing 16+ copies of oskar mRNA displayed no significant association with Egalitarian (F) and the relative amounts of Egalitarian on oskar mRNPs were identical to what was observed in the presence of endogenous, unlabelled Egalitarian ( $F^{\prime}$, blue). (G) Mean signal intensity of Staufen-GFP measured at multiple locations throughout developing oocytes. Size of the oocytes (x-axis) is used as a proxy of developmental time and, along with the morphological clues, for staging of the oocytes (shaded areas as indicated in the panel). (C-G) Error bars show the 95\% confidence interval of the mean.(H) Western blot of input lysates and eluates after Egalitarian RNA immunoprecipitation in the presence (lane 3) or the absence (lane 4) of Staufen. Bait proteins - monomeric EGFP (lane 1), GFP-Staufen (lane 2) and Egalitarian-GFP (lanes 3,4) - are detected by anti-GFP antibody. Anti-tubulin staining served to monitor potential contamination of the eluates. 
bioRxiv preprint doi: https://doi.org/10.1101/2021.04.24.441269; this version posted April 25, 2021. The copyright holder for this preprint (which was not certified by peer review) is the author/funder, who has granted bioRxiv a license to display the preprint in perpetuity. It is made available under aCC-BY-NC-ND 4.0 International license.
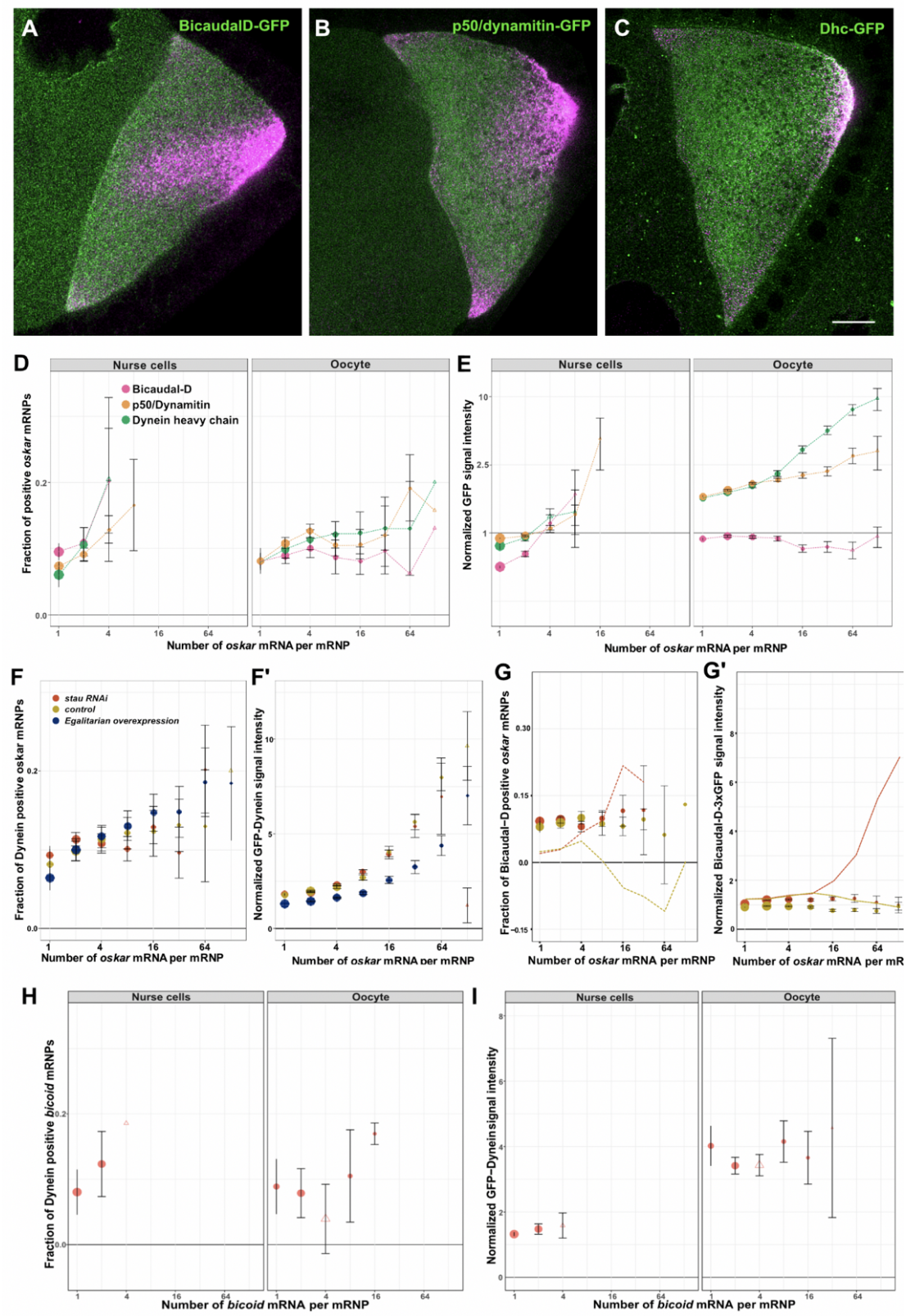

Figure S4: Recruitment of Dynein during the transport of oskar mRNPs.

(A-C) Localization of Bicaudal-D (green, A), p50/dynamitin (green, B) and Dhc (green, C) in egg-chambers during mid-oogenesis. oskar mRNA is shown in magenta. Scale bar represents $10 \mu \mathrm{m}$. (D) Fraction of oskar mRNPs colocalizing with Bicaudal-D (magenta), p50/dynamitin (orange) and Dynein heavy chain (green) in the nurse cells and in the oocyte; mRNPs classified according to oskar mRNA copy number. (E) Normalized GFP signal intensity of Bicaudal-D (magenta), p50/dynamitin (orange) and Dynein heavy chain (green) colocalizing with oskar mRNPs. (F) Fraction of GFP-Dhc positive oskar mRNPs and (F') GFP-Dhc amounts on oskar mRNPs when Staufen levels are reduced (red) and in the presence of excess Egalitarian (dark blue). (G) Fraction of Bicaudal D-3xGFP positive oskar mRNPs and (G') GFP-Dhc amounts on oskar mRNPs when Staufen levels are reduced (red). Mean fractions of Egalitarian-GFP positive oskar mRNPs (G) and mean amounts of Egalitarian-GFP associated with oskar mRNPs (G') are indicated as dashed lines in the appropriate colour. $(\mathrm{H})$ Fraction of GFP-Dhc positive bicoid mRNPs and (I) relative amounts of GFP-Dhc associated with bicoid mRNPs in nurse cells and in the oocyte. 
bioRxiv preprint doi: https://doi.org/10.1101/2021.04.24.441269; this version posted April 25, 2021. The copyright holder for this preprint (which was not certified by peer review) is the author/funder, who has granted bioRxiv a license to display the preprint in perpetuity. It is made available under aCC-BY-NC-ND 4.0 International license.
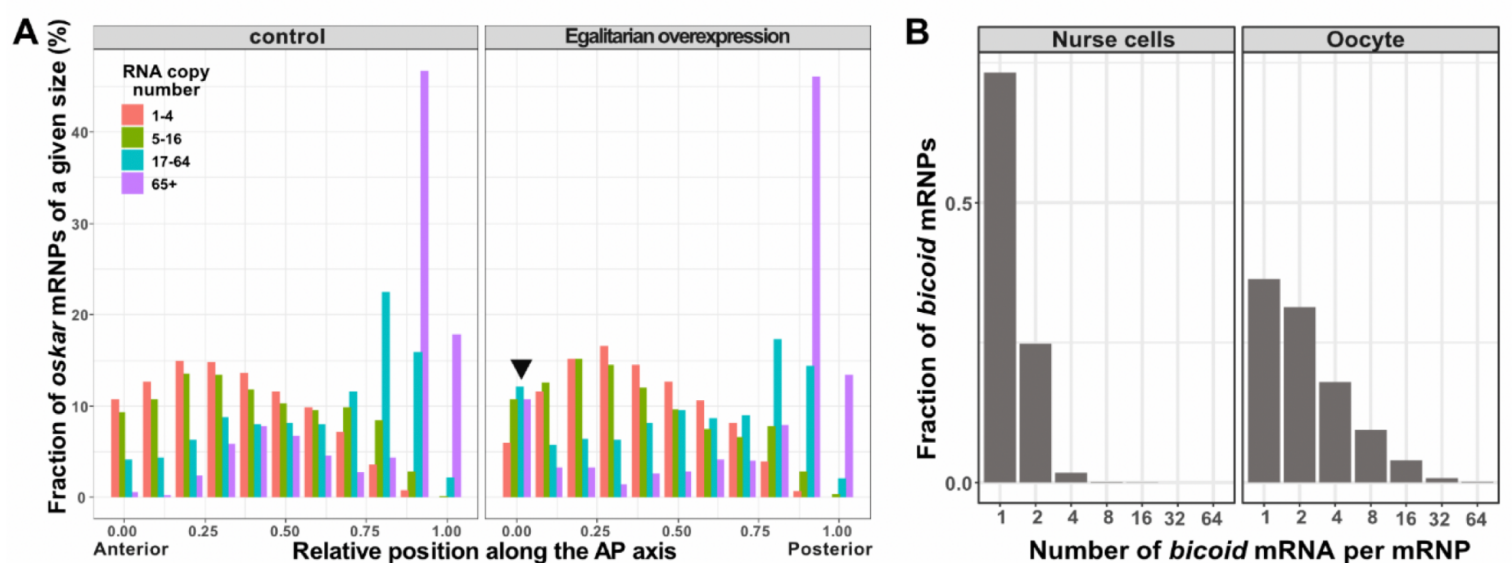

Figure S5:

(A) Relative distribution of oskar mRNPs grouped by RNA content along the anteroposterior axis in wild-type and in Egalitarian overexpressing oocytes. (B) Distribution of the RNA content of bicoid mRNPs in nurse cells and in oocytes during stage 9 of oogenesis. 
bioRxiv preprint doi: https://doi.org/10.1101/2021.04.24.441269; this version posted April 25, 2021. The copyright holder for this preprint

(which was not certified by peer review) is the author/funder, who has granted bioRxiv a license to display the preprint in perpetuity. It is made available under aCC-BY-NC-ND 4.0 International license.
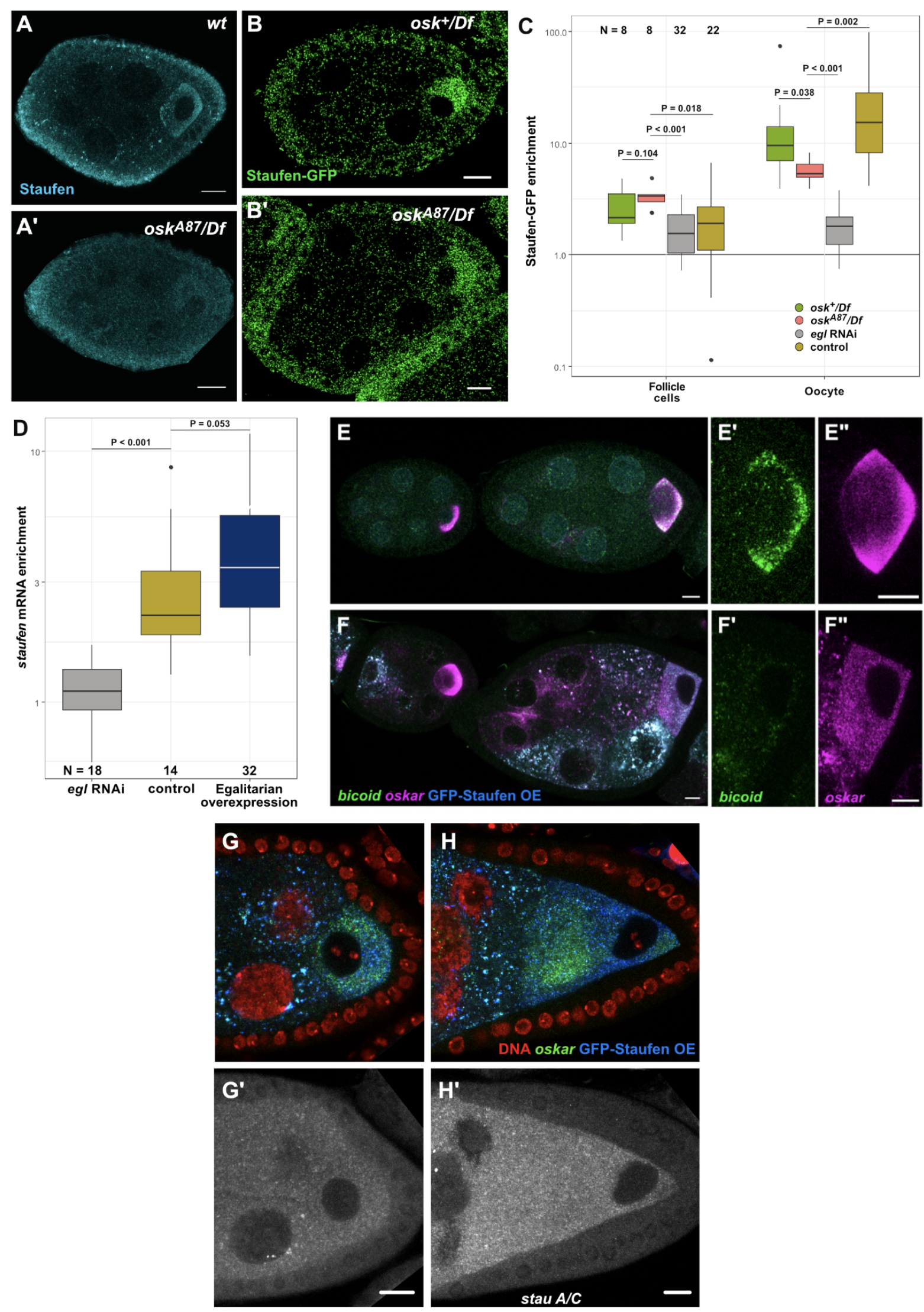
bioRxiv preprint doi: https://doi.org/10.1101/2021.04.24.441269; this version posted April 25, 2021. The copyright holder for this preprint (which was not certified by peer review) is the author/funder, who has granted bioRxiv a license to display the preprint in perpetuity. It is made available under aCC-BY-NC-ND 4.0 International license.

\section{Figure $\mathbf{S 6}$}

(A-B') Staufen protein expression detected via immunofluorescence (blue, $A$ and $A^{\prime}$ ) or by the fluorescent reporter Staufen-GFP ( $B$ and $B^{\prime}$, green) in early egg-chambers in the presence $(A$ and $B$ ) and in complete absence of oskar mRNA ( $A^{\prime}$ and $B^{\prime}$ ). Note that lack of oskar from the oocyte blocks progression of oogenesis beyond stage 6 (Jenny et al., 2006). (C) Enrichment of Staufen-GFP signal in early oocytes with one (green) or no (red) functional oskar allele expressing oskar mRNA, and in oocytes expressing egl RNAi (grey) or control RNAi (brown). Enrichment is relative to the sibling nurse cells in the egg-chamber. Enrichment of Staufen-GFP in somatic follicle cells, which do not express the shRNA, serves as a control. P-values of pairwise Student's t-test are shown. Note that complete lack of oskar mRNA, an abundant binding partner of Staufen, has only a moderate effect on Staufen enrichment in the developing oocyte (also observed in A-B'), whereas knock-down of Egalitarian almost completely abolishes Staufen ooplasmic accumulation. (D) Quantification of the enrichment of staufen mRNA in the oocyte - detected using the stau A/C probe set - in egl RNAi (grey), control RNAi (yellow) and Egalitarian overexpressing oocytes (dark blue). Note that an excess of Egalitarian has a minuscule effect on staufen RNA accumulation in the oocyte, suggesting that in the wild-type, most of the staufen mRNA expressed in the nurse cells is transported into the oocyte. (E-F") Early egg-chambers overexpressing GFP-Staufen ( $F$, blue) under control of the matTub-Gal4 driver. Note that in control oocytes of similar age (E-E"), and in oocytes expressing low levels of GFP-Staufen (F, left egg-chamber), oskar mRNA (E”, F”, magenta) is enriched. Enrichment of oskar and bicoid (E', F', green) mRNAs is greatly reduced in oocytes expressing high levels of GFP-Staufen (F, right egg-chamber). (G-H') Early and mid-oogenetic egg-chambers overexpressing GFP-Staufen (blue) under control of the oskar-Gal4 driver from the beginning of oogenesis. The vast majority of such egg-chambers fails to develop beyond stage $6(G)$ likely as a consequence of greatly reduced ooplasmic accumulation of oskar mRNA (green), which appears to be trapped in the nurse cells in large aggregates associated with GFP-Staufen. Similarly, no accumulation of staufen mRNA is observed in these oskar-Gal4>UASp-GFP-Staufen oocytes (G' and 'H'), where staufen mRNA levels are uniformly high in the germ-line (compare the signal in the follicle cell layer to that in the nurse cells and in the oocyte, see Figure 5). (H, $\left.\mathrm{H}^{\prime}\right)$ In the oocytes occasionally escaping early developmental arrest, we invariably observed failure in nuclear migration from the posterior to the anterior, reflecting a defect in repolarisation of the oocyte microtubule network (Januschke et al., 2006). Consequently, oskar mRNA remains in the center of these oocytes, which - although they complete oogenesis - fail to result in viable progeny. Scale bar represents $5 \mu \mathrm{m}$. 
bioRxiv preprint doi: https://doi.org/10.1101/2021.04.24.441269; this version posted April 25, 2021. The copyright holder for this preprint (which was not certified by peer review) is the author/funder, who has granted bioRxiv a license to display the preprint in perpetuity. It is made available under aCC-BY-NC-ND 4.0 International license.

Video S1 and S2: Live cell imaging of oskMS2-GFP RNPs in control (Video S1) and stau RNAi (Video S2) stage 9 oocytes. Anterior (left) and posterior (right) regions of the same oocyte are shown. oskMS2-GFP signal is rendered in blue-yellow to allow visual appreciation of dim (blue) and bright (yellow) oskar mRNPs.

Video S3 and S4: Ex vivo imaging of oskMS2-GFP RNPs in extracts of control (Video S3) and stau RNAi (Video S4) stage 9 oocytes. oskar mRNPs are shown in green, microtubule plus tips are labeled by EB1-mCherry (magenta). Note the frequent runs of dim oskar mRNPs in the stau RNAi condition (Video S4) 


\section{References}

Abouward, R., and Schiavo, G. (2021). Walking the line: mechanisms underlying directional mRNA transport and localisation in neurons and beyond. Cell. Mol. Life Sci. 78, 2665-2681.

Akhmanova, A., and Hammer, J.A. (2010). Linking molecular motors to membrane cargo. Curr. Opin. Cell Biol. 22, 479-487.

Amrute-Nayak, M., and Bullock, S.L. (2012). Single-molecule assays reveal that RNA localization signals regulate dynein-dynactin copy number on individual transcript cargoes. Nat. Cell Biol. 14, 416-423.

Bauer, K.E., Segura, I., Gaspar, I., Scheuss, V., Illig, C., Ammer, G., Hutten, S., Basyuk, E., Fernández-Moya, S.M., Ehses, J., et al. (2019). Live cell imaging reveals 3'-UTR dependent mRNA sorting to synapses. Nat. Commun. 10, 3178.

Benaglia, T., Chauveau, D., Hunter, D.R., and Young, D. (2009). mixtools : anr package for analyzing finite mixture models. J. Stat. Softw. 32.

Berleth, T., Burri, M., Thoma, G., Bopp, D., Richstein, S., Frigerio, G., Noll, M., and Nüsslein-Volhard, C. (1988). The role of localization of bicoid RNA in organizing the anterior pattern of the Drosophila embryo. EMBO J. 7, 1749-1756.

Brendza, R.P., Serbus, L.R., Duffy, J.B., and Saxton, W.M. (2000). A function for kinesin I in the posterior transport of oskar mRNA and Staufen protein. Science 289, 2120-2122.

Clark, A., Meignin, C., and Davis, I. (2007). A Dynein-dependent shortcut rapidly delivers axis determination transcripts into the Drosophila oocyte. Development 134, 1955-1965.

Dienstbier, M., Boehl, F., Li, X., and Bullock, S.L. (2009). Egalitarian is a selective RNA-binding protein linking mRNA localization signals to the dynein motor. Genes Dev. 23, 1546-1558.

Eliscovich, C., and Singer, R.H. (2017). RNP transport in cell biology: the long and winding road. Curr. Opin. Cell Biol. 45, 38-46.

Ephrussi, A., and Lehmann, R. (1992). Induction of germ cell formation by oskar. Nature 358, 387-392.

Ephrussi, A., Dickinson, L.K., and Lehmann, R. (1991). Oskar organizes the germ plasm and directs localization of the posterior determinant nanos. Cell $66,37-50$.

Ferrandon, D., Elphick, L., Nüsslein-Volhard, C., and St Johnston, D. (1994). Staufen protein associates with the 3'UTR of bicoid mRNA to form particles that move in a microtubule-dependent manner. Cell 79, 1221-1232.

Gaspar, I. (2011). Microtubule-based motor-mediated mRNA localization in Drosophila oocytes and embryos. Biochem. Soc. Trans. 39, 1197-1201.

Gaspar, I., and Ephrussi, A. (2017). Ex vivo Ooplasmic Extract from Developing Drosophila Oocytes for Quantitative TIRF Microscopy Analysis. Bio Protoc 7.

Gaspar, I., Yu, Y.V., Cotton, S.L., Kim, D.-H., Ephrussi, A., and Welte, M.A. (2014). Klar ensures thermal robustness of oskar localization by restraining RNP motility. J. Cell Biol. 206, 199-215.

Gaspar, I., Wippich, F., and Ephrussi, A. (2017). Enzymatic production of single-molecule FISH and RNA capture probes. RNA 23, 1582-1591. 
Gáspár, I., Sysoev, V., Komissarov, A., and Ephrussi, A. (2017). An RNA-binding atypical tropomyosin recruits kinesin-1 dynamically to oskar mRNPs. EMBO J. 36, 319-333.

Ghosh, S., Marchand, V., Gáspár, I., and Ephrussi, A. (2012). Control of RNP motility and localization by a splicing-dependent structure in oskar mRNA. Nat. Struct. Mol. Biol. 19, 441-449.

Glock, C., Heumüller, M., and Schuman, E.M. (2017). mRNA transport \& local translation in neurons. Curr. Opin. Neurobiol. 45, 169-177.

Gratz, S.J., Cummings, A.M., Nguyen, J.N., Hamm, D.C., Donohue, L.K., Harrison, M.M., Wildonger, J., and O'Connor-Giles, K.M. (2013). Genome engineering of Drosophila with the CRISPR RNA-guided Cas9 nuclease. Genetics 194, 1029-1035.

Heber, S., Gáspár, I., Tants, J.-N., Günther, J., Moya, S.M.F., Janowski, R., Ephrussi, A., Sattler, M., and Niessing, D. (2019). Staufen2-mediated RNA recognition and localization requires combinatorial action of multiple domains. Nat. Commun. 10, 1659.

Heraud-Farlow, J.E., Sharangdhar, T., Li, X., Pfeifer, P., Tauber, S., Orozco, D., Hörmann, A., Thomas, S., Bakosova, A., Farlow, A.R., et al. (2013). Staufen2 regulates neuronal target RNAs. Cell Rep. 5, 1511-1518.

Jambor, H., Mueller, S., Bullock, S.L., and Ephrussi, A. (2014). A stem-loop structure directs oskar mRNA to microtubule minus ends. RNA 20, 429-439.

Januschke, J., Gervais, L., Dass, S., Kaltschmidt, J.A., Lopez-Schier, H., St Johnston, D., Brand, A.H., Roth, S., and Guichet, A. (2002). Polar transport in the Drosophila oocyte requires Dynein and Kinesin I cooperation. Curr. Biol. 12, 1971-1981.

Januschke, J., Gervais, L., Gillet, L., Keryer, G., Bornens, M., and Guichet, A. (2006). The centrosome-nucleus complex and microtubule organization in the Drosophila oocyte. Development 133, 129-139.

Jenny, A., Hachet, O., Závorszky, P., Cyrklaff, A., Weston, M.D.J., Johnston, D.S., Erdélyi, M., and Ephrussi, A. (2006). A translation-independent role of oskar RNA in early Drosophila oogenesis. Development 133, 2827-2833.

Kim, Y.K., Furic, L., Desgroseillers, L., and Maquat, L.E. (2005). Mammalian Staufen1 recruits Upf1 to specific mRNA 3'UTRs so as to elicit mRNA decay. Cell 120, 195-208.

Laver, J.D., Li, X., Ancevicius, K., Westwood, J.T., Smibert, C.A., Morris, Q.D., and Lipshitz, H.D. (2013). Genome-wide analysis of Staufen-associated mRNAs identifies secondary structures that confer target specificity. Nucleic Acids Res. 41, 9438-9460.

Lenth, R.V. (2016). Least-Squares Means: the $R$ package Ismeans. J. Stat. Softw. 69, 1-33.

Little, S.C., Sinsimer, K.S., Lee, J.J., Wieschaus, E.F., and Gavis, E.R. (2015). Independent and coordinate trafficking of single Drosophila germ plasm mRNAs. Nat. Cell Biol. 17, 558-568.

Liu, Y., Salter, H.K., Holding, A.N., Johnson, C.M., Stephens, E., Lukavsky, P.J., Walshaw, J., and Bullock, S.L. (2013). Bicaudal-D uses a parallel, homodimeric coiled coil with heterotypic registry to coordinate recruitment of cargos to dynein. Genes Dev. 27, 1233-1246.

Mach, J.M., and Lehmann, R. (1997). An Egalitarian-BicaudalD complex is essential for oocyte specification and axis determination in Drosophila. Genes Dev. 11, 423-435.

Marchand, V., Gaspar, I., and Ephrussi, A. (2012). An intracellular transmission control 
protocol: assembly and transport of ribonucleoprotein complexes. Curr. Opin. Cell Biol. 24, 202-210.

Martin, K.C., and Ephrussi, A. (2009). mRNA localization: gene expression in the spatial dimension. Cell 136, 719-730.

McClintock, M.A., Dix, C.I., Johnson, C.M., McLaughlin, S.H., Maizels, R.J., Hoang, H.T., and Bullock, S.L. (2018). RNA-directed activation of cytoplasmic dynein-1 in reconstituted transport RNPs. Elife 7.

Micklem, D.R., Adams, J., Grünert, S., and St Johnston, D. (2000). Distinct roles of two conserved staufen domains in oskar mRNA localization and translation. EMBO J. 19, 1366-1377.

Mofatteh, M., and Bullock, S.L. (2017). SnapShot: Subcellular mRNA Localization. Cell 169, 178-178.e1.

Mohr, S., Kenny, A., Lam, S.T.Y., Morgan, M.B., Smibert, C.A., Lipshitz, H.D., and Macdonald, P.M. (2021). Opposing roles for Egalitarian and Staufen in transport, anchoring and localization of oskar mRNA in the Drosophila oocyte. PLoS Genet. 17, e1009500.

Navarro, C., Puthalakath, H., Adams, J.M., Strasser, A., and Lehmann, R. (2004). Egalitarian binds dynein light chain to establish oocyte polarity and maintain oocyte fate. Nat. Cell Biol. 6, 427-435.

Neuman-Silberberg, F.S., and Schüpbach, T. (1993). The drosophila dorsoventral patterning gene gurken produces a dorsally localized RNA and encodes a TGFa-like protein. Cell 75, 165-174.

Palacios, I.M., and St Johnston, D. (2002). Kinesin light chain-independent function of the Kinesin heavy chain in cytoplasmic streaming and posterior localisation in the Drosophila oocyte. Development 129, 5473-5485.

Park, E., Gleghorn, M.L., and Maquat, L.E. (2013). Staufen2 functions in Staufen1-mediated mRNA decay by binding to itself and its paralog and promoting UPF1 helicase but not ATPase activity. Proc Natl Acad Sci USA 110, 405-412.

Parton, R.M., Hamilton, R.S., Ball, G., Yang, L., Cullen, C.F., Lu, W., Ohkura, H., and Davis, I. (2011). A PAR-1-dependent orientation gradient of dynamic microtubules directs posterior cargo transport in the Drosophila oocyte. J. Cell Biol. 194, 121-135.

Rom, I., Faicevici, A., Almog, O., and Neuman-Silberberg, F.S. (2007). Drosophila Dynein light chain (DDLC1) binds to gurken mRNA and is required for its localization. Biochim. Biophys. Acta 1773, 1526-1533.

R Core Team (2014). R: A language and environment for statistical computing. R Foundation for StatisticalComputing.

Sanghavi, P., Laxani, S., Li, X., Bullock, S.L., and Gonsalvez, G.B. (2013). Dynein associates with oskar mRNPs and is required for their efficient net plus-end localization in Drosophila oocytes. PLoS ONE 8, e80605.

Sanghavi, P., Liu, G., Veeranan-Karmegam, R., Navarro, C., and Gonsalvez, G.B. (2016). Multiple roles for egalitarian in polarization of the drosophila egg chamber. Genetics 203, 415-432.

Schuldt, A.J., Adams, J.H., Davidson, C.M., Micklem, D.R., Haseloff, J., St Johnston, D., and 
Brand, A.H. (1998). Miranda mediates asymmetric protein and RNA localization in the developing nervous system. Genes Dev. 12, 1847-1857.

Schüpbach, T., and Wieschaus, E. (1989). Female sterile mutations on the second chromosome of Drosophila melanogaster. I. Maternal effect mutations. Genetics 121, 101-117.

Sladewski, T.E., Billington, N., Ali, M.Y., Bookwalter, C.S., Lu, H., Krementsova, E.B., Schroer, T.A., and Trybus, K.M. (2018). Recruitment of two dyneins to an mRNA-dependent Bicaudal D transport complex. Elife 7.

St Johnston, D. (2005). Moving messages: the intracellular localization of mRNAs. Nat. Rev. Mol. Cell Biol. 6, 363-375.

St Johnston, D., Beuchle, D., and Nüsslein-Volhard, C. (1991). Staufen, a gene required to localize maternal RNAs in the Drosophila egg. Cell 66, 51-63.

St Johnston, D., Brown, N.H., Gall, J.G., and Jantsch, M. (1992). A conserved double-stranded RNA-binding domain. Proc Natl Acad Sci USA 89, 10979-10983.

Sysoev, V.O., Fischer, B., Frese, C.K., Gupta, I., Krijgsveld, J., Hentze, M.W., Castello, A., and Ephrussi, A. (2016). Global changes of the RNA-bound proteome during the maternal-to-zygotic transition in Drosophila. Nat. Commun. 7, 12128.

Trovisco, V., Belaya, K., Nashchekin, D., Irion, U., Sirinakis, G., Butler, R., Lee, J.J., Gavis, E.R., and St Johnston, D. (2016). bicoid mRNA localises to the Drosophila oocyte anterior by random Dynein-mediated transport and anchoring. Elife 5.

Vanzo, N.F., and Ephrussi, A. (2002). Oskar anchoring restricts pole plasm formation to the posterior of the Drosophila oocyte. Development 129, 3705-3714.

Vazquez-Pianzola, P., Schaller, B., Colombo, M., Beuchle, D., Neuenschwander, S., Marcil, A., Bruggmann, R., and Suter, B. (2017). The mRNA transportome of the BicD/Egl transport machinery. RNA Biol. 14, 73-89.

Wickham, H. (2016). ggplot2 - Elegant Graphics for Data Analysis (New York, NY:

Springer-Verlag New York).

Williams, L.S., Ganguly, S., Loiseau, P., Ng, B.F., and Palacios, I.M. (2014). The auto-inhibitory domain and ATP-independent microtubule-binding region of Kinesin heavy chain are major functional domains for transport in the Drosophila germline. Development 141, 176-186.

Wu, B., Chao, J.A., and Singer, R.H. (2012). Fluorescence fluctuation spectroscopy enables quantitative imaging of single mRNAs in living cells. Biophys. J. 102, 2936-2944.

Zimyanin, V.L., Belaya, K., Pecreaux, J., Gilchrist, M.J., Clark, A., Davis, I., and St Johnston, D. (2008). In vivo imaging of oskar mRNA transport reveals the mechanism of posterior localization. Cell 134, 843-853. 